Portland State University

PDXScholar

$1-1-2011$

\title{
Identifying Victims of Domestic Minor Sex Trafficking in a Juvenile Custody Setting
}

Jonathan Dickinson Dabney

Portland State University

Follow this and additional works at: https://pdxscholar.library.pdx.edu/open_access_etds Let us know how access to this document benefits you.

\section{Recommended Citation}

Dabney, Jonathan Dickinson, "Identifying Victims of Domestic Minor Sex Trafficking in a Juvenile Custody Setting" (2011). Dissertations and Theses. Paper 305.

https://doi.org/10.15760/etd.305

This Thesis is brought to you for free and open access. It has been accepted for inclusion in Dissertations and Theses by an authorized administrator of PDXScholar. Please contact us if we can make this document more accessible: pdxscholar@pdx.edu. 


\title{
Identifying Victims of Domestic Minor Sex Trafficking in a Juvenile Custody Setting
}

\author{
by \\ Jonathan Dickinson Dabney
}

\begin{abstract}
A thesis submitted in partial fulfillment of the requirements for the degree of
\end{abstract}

\author{
Master of Science \\ in \\ Criminology and Criminal Justice
}

\begin{abstract}
Thesis Committee:
Emily Salisbury, Chair

Danielle McGurrin

Jody Sundt
\end{abstract}

Portland State University

2011 


\begin{abstract}
Domestic Minor Sex Trafficking (DMST) is a severe form of child sexual exploitation. Thus far, DMST studies have been qualitative or relied on secondary data. There has been no quantitative attempt to directly identify victims in a methodical way in order to determine the prevalence of DMST at a local level or the nature and strengths of its correlates. The present study used a three-tiered screening process to identify victims of DMST in a juvenile detention center. All youth taken into custody over a three and a half month period $(N=738)$ received a short assessment to identify those most at risk and in need of additional screening. During the study, six youth were identified as DMST victims and statistically significant differences were found between youth referred for additional screening $(N=47)$ and youth who were not. The results suggest that detention and probation staff identified the presence of DMST risk factors in youth screen interviews and were making referral decisions based on the presence of those risk factors. Practical implications of the findings are discussed along with suggestions for future research.
\end{abstract}




\section{Acknowledgments}

I wish to extend my deepest gratitude to a number of people for making this thesis possible:

First and foremost, I would like thank Dr. Emily J. Salisbury for developing the Tier 1 screen interview and three-tiered screening process, for providing me with the opportunity to empirically test the process, for overseeing the project from start to finish, and for being my thesis chair. Your guidance, support, feedback, and suggestions over the nine months it took to complete this project were invaluable.

Thank you to Dr. Danielle McGurrin and Dr. Jody Sundt for being my readers and part of my thesis committee. Your recommendations helped push me to be more confident and assertive.

Thank you to Kelli Russell for helping to develop the Tier 1 screen interview and three-tiered screening process, and for laying the groundwork with Clark County Juvenile Court which allowed this project to be possible.

Thank you to Sarah Lazzari for the hours you spent helping me enter the Tier 1 screen interview data.

Thank you to my family for your emotional and financial support.

Thank you to Shared Hope International for allowing your screen instruments to be used as part of this study.

Thank you to the victim advocates from both the YWCA in Vancouver, WA and Sexual Assault Resource Center (SARC) in Portland, OR who conducted the Tier 3 
interviews and provided assistance and advocacy for the victims identified during the study.

Lastly, I would like to thank the Clark County Juvenile Court for allowing this project to take place. Thank you for the time, energy, resources, and commitment you devoted over the course of several months. Thank you to those who volunteered as members of the Response Team. A special thanks to Nicole Steinman for managing the entire project on Clark County's end. Without your help, oversight, and diligence, this project would not have been possible. 


\section{Table of Contents}

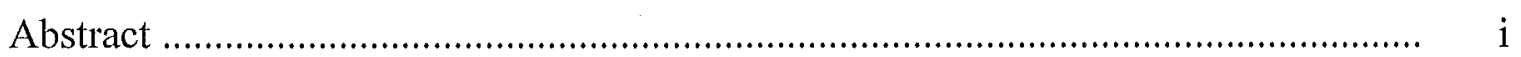

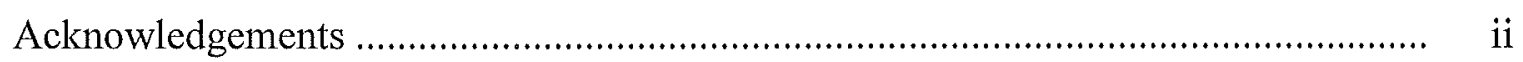

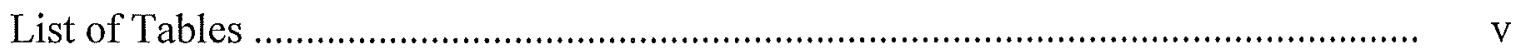

Chapter 1

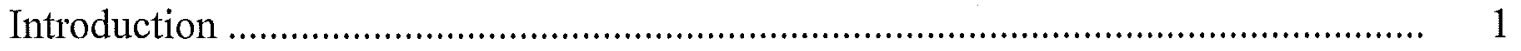

Chapter 2

Review of Literature .................................................................................. 4

Chapter 3

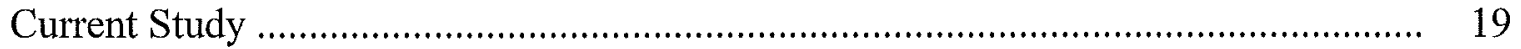

Chapter 4

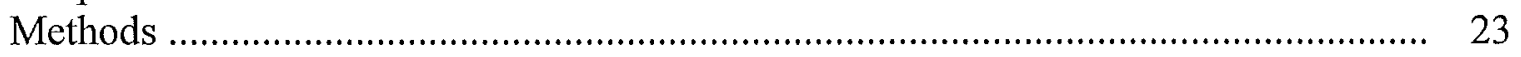

Chapter 5

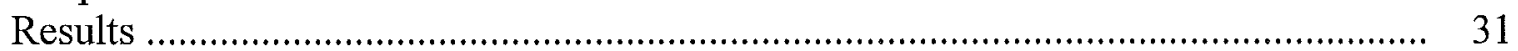

Chapter 6

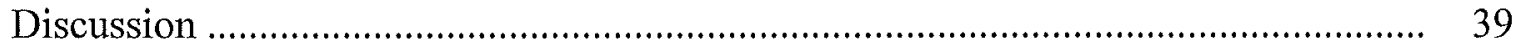

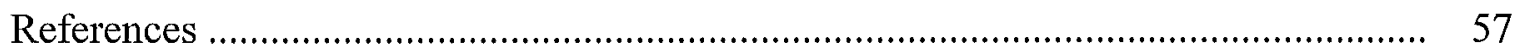

Appendices

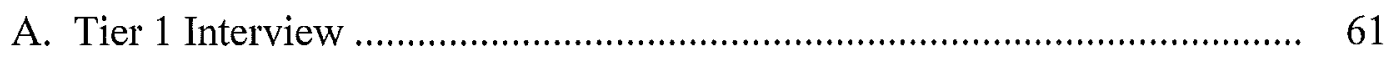

B. Tier 2 Interview ....................................................................... 63

C. Tier 3 Interview ......................................................................... 66

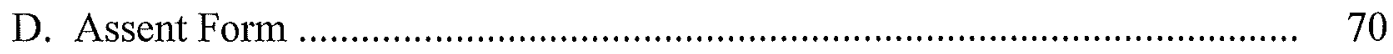




\section{List of Tables}

Table 1. Demographic characteristics of youth receiving Tier 1 ............................ 51

Table 2. Number of youth receiving one or more Tier 1 interviews.......................... 52

Table 3. Characteristics of youth referred to a Tier 2 interview............................... 53

Table 4. Chi-square and Pearson's r values for Tier 1 variables and whether or not youth was referred to a Tier 2 ........................................................

Table 5. Characteristics and Risk Factors of Confirmed DMST Victims.................... 55

Table 6. Criminal Histories of Confirmed DMST Victims...................................... 56 


\section{Introduction}

The use of children for sexual purposes by adults has existed for centuries in various forms in all societies and cultures. The first age of consent law was not established until 1275 in England wherein sex with a female under the age of 12 was considered rape and classified as a misdemeanor (Robertson, 2008a). In the United States, by 1880,37 states had set the age of consent at 10 years old (Robertson, 2008b). Over the course of history, notions of what constitutes acceptable behavior between an adult and a child has changed dramatically. In recent years, however, child sexual exploitation has been repackaged, re-labeled, and re-framed as a severe form of child maltreatment. As a result of the 2000 Trafficking Victims Protection Act (TVPA), a broad range of behaviors involving individuals under the age of 18 are now classified as severe forms of human trafficking.

The sexual exploitation of children exists on a continuum with domestic minor sex trafficking (DMST) being the most severe and extreme form. Qualitative studies have been useful in researching this new phenomena and providing detailed accounts of victimization. Thus far, qualitative research has shed light on how youth are procured for sexual exploitation (Ashley, 2008; Boxill \& Richardson, 2007; OJJDP, 2002; Smith, Vardaman, \& Snow, 2009), the nature and types of sexual exploitation youth experience (Ashley, 2008; Smith et al., 2009), and risk factors that increase the likelihood of sexual victimization (Ashley, 2008; Boxill \& Richardson, 2007; Clawson, Dutch, Salomon, \& Grace, 2009; OJJDP, 2002; Smith et al., 2009; Spangenberg, 2001; Tyler, Hoyt, \& Whitbeck, 2000). However, to date there has been no quantitative attempt to identify 
victims in a methodical way in order to determine either the prevalence of DMST at a local level or the nature and strengths of its correlates. As a result, many, if not most, existing prevalence estimates of DMST are "crude" and "scientifically indefensible" (Mitchell, Finkelhor, \& Wolak, 2010, p. 31).

The present study is the first of its kind to attempt to systematically identify victims of domestic minor sex trafficking (DMST) in a juvenile custody setting. All youth taken into custody over a three and a half month period at the Clark County Juvenile Detention Center in Vancouver, WA received a short assessment as part of their standardized intake process in order to strategically identify those most at risk of victimization and in need of additional screening. The expectation was that such a process would increase the timely and accurate identification of victims in order to divert them from the formal juvenile justice system and link them to appropriate social, mental, and health services in the community.

To this end, the current study examines whether a Response Team, comprised of detention and probation staff, identified the presence of DMST risk factors in youth screen interviews, that prior research suggests are associated with DMST victims. The expectation is that the initial screen interview will uncover the presence of certain risk factors and assist detention and probation staff in identifying youth who are in need of additional in-depth assessment to determine their DMST status. Significant differences between youth who were referred for additional assessment and those who were not will indicate that detention and probation staff were making referral decisions based on the 
presence of DMST risk factors. A qualitative analysis is also provided of the presence of risk factors, or lack thereof, of youth confirmed as victims during the course of the study. 


\section{Review of Literature}

The current state of empirical knowledge about domestic minor sex trafficking (DMST) is quite limited. This is due, in part, to DMST being a highly specific form of human trafficking, narrowed down to minors, and only those who are citizens or lawful permanent residents of the United States. A good portion of what is currently known about human trafficking as a general topic is the result of funding made available to NonGovernmental Organizations (NGOs) and faith-based organizations through the Trafficking Victims Protection Act (TVPA) and its subsequent reauthorizations. The principle focus thus far has been for "programs, housing, and services for alien victims who are brought into this country for the purposes of trafficking" (Boxill \& Richardson, 2007, p. 141). Being that a majority of the literature addresses trafficking into the United States from various source countries, often without a specific focus on sex trafficking or minors, most of what is currently known does not generalize to the phenomenon of DMST in the United States.

\section{Domestic Minor Sex Trafficking}

Domestic Minor Sex Trafficking (DMST) is a "term coined by Shared Hope International to identify the commercial sexual exploitation of children under 18 years of age who are U.S. citizens or lawful permanent residents" (Smith et al., 2009, p. 9). Prior to this label, the phenomenon was known, and often still is, as child prostitution, the commercial sexual exploitation of a child (CSEC), or the commercial sexual exploitation of a minor (CSEM). Regardless of the name, the exchange is considered exploitation because "it comes about in a relationship of unequal economic, cognitive and psycho- 
social power" that is both emotionally and physically detrimental to the youth (Spangenberg, 2001, p. 3).

With the passage of the 2000 Trafficking Victims Protection Act (TVPA), DMST is considered a specific and severe form of human trafficking. As a result of the TVPA and its subsequent reauthorizations $(2003,2005$, and 2008), human trafficking has received a great deal of national attention among criminal justice and social service researchers, practitioners, and policy makers. Unfortunately, despite ten years since its passage, as of this writing, little is empirically known about the nature, scope, and causes of DMST in the United States. Perhaps this is partially a reflection of the bill itself.

The TVPA of 2000 is an 86 page bill. Although titled the Trafficking Victims Protections Act, trafficking in persons is only one of three sections covered within the bill. Sex trafficking, let alone of a minor, occupies a relatively small portion of the bill which contains 46 pages of the Violence Against Women Act and 12 pages of Miscellaneous Provisions ranging from Aimee's Law to anti-terrorism. More recently, of the 48 page 2008 reauthorization, less than two pages are devoted to nonimmigrant victims including children compared to more than eight pages addressing immigrant victims within the United States.

Under 22 U.S.C. $§ 7102$, "the term 'sex trafficking' means the recruitment, harboring, transportation, provision, or obtaining of a person for the purpose of a commercial sex act" (TVPA, 2000, p. 8). A 'commercial sex act' is defined as "any sex act on account of which anything of value is given to or received by any person" (TVPA, 
2000, p. 7). Within 22 U.S.C. $\S 7102$, "severe forms of trafficking in persons" are defined as:

(A) sex trafficking in which a commercial sex act is induced by force, fraud, or coercion, or in which the person induced to perform such act has not attained 18 years of age; or

(B) the recruitment, harboring, transportation, provision, or obtaining of a person for labor or services, through the use of force, fraud, or coercion for the purpose of subjection to involuntary servitude, peonage, debt bondage, or slavery. (TVPA, 2000, p. 8)

By nature of the definition, sex trafficking (including DMST) is perhaps a bit of a misnomer. 'Trafficking' conjures up images of movement or transportation as is the case with the illicit drug trade. Contrary to what the label 'sex trafficking' implies though, to be considered a victim under the TVPA does not require that the individual be moved or transported; transportation is only one of five ways that a person can be trafficked.

With regard to age, individual states are free to establish their own age of sexual consent under our system of federalism. A majority (34) have set the age of consent at 16 (Glosser, Gardiner, \& Fishman, 2004). However, since the crime of DMST involves a commercial sex act, it is considered an act of commerce thereby bringing the age of consent under the federal U.S. Code wherein a minor is defined as a child under the age of 18 (FBI, n.d.). Because a minor cannot legally consent to a commercial sex act, neither force, fraud, or coercion are necessary elements of DMST. Therefore, any minor who is induced to perform a commercial sex act is considered a victim.

Prevalence

The few available estimates on the number of alleged DMST victims or sexually exploited children in the United States vary greatly from a low of 100,000 annually 
(Smith et al., 2009) to a high of 500,000 to 10 million annually (Boxill \& Richardson 2007). However, given the numerous methodological problems with current data (as will be discussed), citing such figures runs the risk of contributing to the 'Woozle Effect'. First identified in family violence research and subsequently found in hard to measure or new phenomenon,

The Woozle Effect begins when one investigator reports a finding, often with qualifications (e.g., that the sample was small and not generalizable). A second investigator then cites the first study's data, but without the qualifications. Others then cite both reports, and 'the qualified data gain the status of an unqualified, generalizable truth'. (Weiner \& Hala, 2008, p. 8; Gelles, 1980, p. 880)

Indeed, fact checking the above estimate cited by Boxill and Richardson reveals that the figure is actually an estimate by Willis and Levy (2002) of the number of prostituted children worldwide. Boxill and Richardson removed the context and cited the figure as an estimate of child prostitution "in America today" (2007, p.139).

Similarly, in an extensive literature review of human trafficking research publications from 1990 through 2006, Weiner and Hala (2008) found a total of 114 prevalence estimates cited in 45 different publications of which only one was an original study. Most notably, they found that even "the estimates featured in U.S. government reports...resemble [what is known as] a 'quantifact,' a figure whose 'value and veracity accumulates as it circulates,' despite its uncertain basis" (p. 9, 10; Comaroff \& Comaroff, 2006, p. 210).

As the above quotation implies, official data do not provide much insight into the prevalence or scope of DMST in the United States. In their national study on juvenile prostitution, Mitchell, Finkelhor, and Wolak (2010) found that only 5\% of law 
enforcement agencies in 2005 arrested or detained a juvenile for prostitution. FBI Uniform Crime Reporting (UCR) data indicate that 1.5 million juveniles were arrested in 2009 , accounting for $14.9 \%$ of violent crime arrests and $24.4 \%$ of property crime arrests. Less than 1,100 juveniles were arrested for prostitution or commercialized vice, of whom 844 (78\%) where female (UCR, 2009). In terms of those deemed most 'at risk' for sexual victimization in 2009 , there were 73,794 recorded arrests for runaway, of whom $55 \%$ were female (UCR, 2009).

On the surface, such low numbers may give the impression that juvenile prostitution is not a common phenomenon in the United States and relatively few are at risk of victimization. However, a study by Farrell, McDevitt, and Fahy (2010) concluded that the relatively low numbers of general human trafficking cases identified by law enforcement may be attributable to both a lack of training and ability to properly identify and investigate such cases. Tyldum and Brunovskis (2005) assert that the number of general human trafficking "cases registered by law enforcement might be an indicator of the functionality of the law enforcement apparatus" rather than a good estimate of the actual number of victims (p. 23). This same argument can be made for cases of juvenile prostitution or DMST.

Official UCR arrest data may also primarily reflect juveniles who work in street prostitution, the most visible and easiest form to detect. However, street prostitution is only the tip of the iceberg representing less than $20 \%$ of all prostitution (Scott \& Dedel, 2006). A 2004 OJJDP report by Finkelhor and Ormrod noted that upon arrest, law enforcement may charge youth engaged in prostitution with masking charges rather than 
with prostitution as a way to detain them and get them connected with social services. In addition, available research has suggested that most youth engaged in prostitution were not properly identified as such during their arrest. One reason was that youth were often arrested and adjudicated on prostitution related charges (or masking charges) such as loitering, curfew, runaway, or minor in possession (Ashley, 2008; Smith et al., 2009). In her study of prostituted juveniles in Illinois from 1994 to 2004, Ashley (2008) found that prostituted youth had an average of 10 arrests for such masking charges. On a similar note, juveniles engaged in prostitution were sometimes not properly identified as juveniles by law enforcement upon arrest. Juvenile victims often had identifications taken away by their pimps and were provided with fraudulent identification (Smith et al., 2009) and even phony social security numbers (Spangenberg, 2001) to conceal their identity, resulting in their being processed as adults (Ashley, 2008). For instance, Mitchell et al. (2010) found that 13\% of prostituted youth with third party exploiters had false identification versus $3 \%$ who were engaged in prostitution on their own. Such phenomena clearly mask the true prevalence of the problem and contribute to the difficulty in accurately identifying victims.

Finkelhor and Ormrod (2004) examined patterns within identified cases of juvenile prostitution from 1997-2000 using data obtained from the FBI's National Incident-Based Reporting System (NIBRS). Their report found that $61 \%$ of juvenile prostitution offenders known to police were male. Overall, males were somewhat older, operated more often outdoors, and were more often arrested and charged as prostitution offenders. In contrast, females were more likely to be 15 years old or younger and 
treated as victims. The authors concluded that age of consent laws partially contributed to whether a juvenile was arrested and charged for prostitution rather than being considered a victim. Consistent with other research, the report found that female juveniles engaged in prostitution were frequently under the control of a pimp (although they did not provide a concrete percentage) whereas male behavior usually reflected survival sex. Survival sex refers to the selling or exchange of sex to secure subsistence needs such as food, clothing, shelter, money, or drugs (Colby, 2011; Green, Ennett, \& Ringwalt, 1999). Unfortunately, while such findings are important and informative, the study only included data on 241 incidents known to the police from 76 agencies in 13 states. This is principally a result of the NIBRS program being in its infancy at the time.

The National Incidence Studies of Missing, Abducted, Runaway, and Thrownaway Children (NISMART) are an additional source from which to gauge the annual number of youth at greater risk of DMST victimization. The most recent series of NISMART reports are based on data and interviews from a variety of sources covering a 12 month period from 1997 to 1999 . According to their estimates, in 1999, there were nearly 1.7 million runaway or thrownaway children in the United States (Hammer, Finkelhor, \& Sedlak, 2002). This statistic is cited by various authors of DMST related studies to suggest the potential number of victims (Ashley, 2008; OJJDP, 2002; Smith et. al., 2009). However, what these studies fail to mention is that only $0.4 \%(6,300)$ of children had not returned home during the course of the study (Hammer et al., 2002). Furthermore, to be considered a runaway, the child must have been gone for at least one night and if over the age of 15 , at least two nights. What the NISMART reports found 
however, is that "most runaway episodes...[were] brief, lasting no longer than a day or two" (Hammer, Finkelhor, Sedlak, \& Porcellini, 2004, p. 3).

The NISMART reports are a classic example of how the operational definition of a term influences what is ultimately measured. One category of missing children is caretaker missing, defined as an "episode during which the child's whereabouts were unknown to the primary caretaker, with the result that the caretaker was alarmed for at least 1 hour and tried to locate the child" (Hammer et al., 2004, p. 3). Consequently, whether a child is classified as 'missing' in this case is not necessarily a matter of the child's circumstance or actual condition, rather the state of mind and knowledge of the child's caretaker (Sedlak, Finkelhor, Hammer, \& Schultz, 2002). Caretaker missing accounted for over three quarters of the total number of missing children of whom only $48 \%$ actually ran away (Hammer et al., 2004, p. 9). It is also important to mention that only $0.2 \%$ of all caretaker missing children were not subsequently located or returned home (Sedlak et al., 2002).

In summary, available estimates that attempt to describe either the annual number of DMST victims or those at risk of DMST victimization are unreliable and even contradictory (Mitchell et al., 2010). In their 2008 final report on the bibliography of research-based literature on general human trafficking, Gozdziak and Bump strongly stated that "the dominant anti-trafficking discourse is not evidence-based...[and has] taken place without a clear idea of the extent of the problem or a uniformed methodology for determining the scope of the issue" (p. 43). Furthermore, they found that "reliance on unrepresentative samples is widespread...[and] the well known dangers of generalizing 
from small convenience samples and from anecdotal stories are routinely ignored in the literature about human trafficking" (p. 44).

Various studies suggested different reasons for the absence of valid and reliable measures. David (2010) pointed out that many of the terms contained in the definition of "trafficking in persons" are open to wide interpretation (p. 237). According to Boxill and Richardson (2007), juvenile justice, child welfare, and law enforcement agencies "each view the issue through different lenses, so that reporting and documentation are fragmented" (p. 140). Clawson et al. (2009) cited the covert nature of the crime and lack of consistent definitions for the purposes of recording, classifying, or identifying victims. Farrell et al. (2010) drew parallels from the current situation to prior difficulties in identifying and responding to other new crimes such as stalking, hate crimes, and domestic violence. Further complicating matters is the reality that DMST victims constitute what is referred to as a hidden population. Tyldum and Brunovskis (2005) define a hidden population as "a group of individuals for whom the size and boundaries are unknown, and for whom no sampling frame exists" (p. 18).

Despite the numerous limitations of available prevalence research, what has been sufficiently established is that DMST is a crime that does, in fact, occur in the United States, albeit in unknown numbers. Whether there are 1,000 victims or 1 million, further research is both justified and necessary. Thus far, victims have been identified in a haphazard and unsystematic way. As evidenced above, there is a clear need for measures that are valid, reliable, and based on empirical research. In the absence of such measures, practitioners and policy makers run the risk of implementing programs and interventions 
that are ineffective and may even be harmful to those they are designed to help.

Furthermore, practitioners, policy makers, social control agents, special interest groups, and the media may be contributing to a 'moral panic'.

According to Goode and Ben-Yehuda (1994), disproportionality is one of five aspects of a moral panic wherein "the concern is out of proportion to the nature of the threat, that it is, in fact, considerably greater than that which a sober empirical evaluation could support" (p. 158). The criteria of disproportionality is met "if the attention paid to [the] given condition at one point in time is vastly greater than that paid to it during a previous or later time without any corresponding increase in objective seriousness" (p. 158). While a full scale discussion of moral panics is beyond the scope of this study, recent times have seen a number of moral panics specific to juveniles including, but not limited to, girls' violence, teenage pregnancy, school violence, bullying, the juvenile 'superpredator', youth gangs, and prescription drug abuse. In addition to the fear generated by such phenomena being disproportionate to what would be warranted by empirical evidence, the above have all existed for decades, if not centuries, prior to being thrust into the spot light. More importantly, each has resulted in far reaching and costly policies, legislation, and crime control strategies as is the current case with DMST. In Oregon alone, there are currently six proposed bills in the 2011 legislative session related to reducing the demand for DMST (i.e., SB425, SB426, SB427, SB429, SB430, SJR28).

\section{Victim Characteristics}

Qualitative studies provide a rich foundation early on in the process of researching new or difficult to measure phenomenon. Thus far, such studies, albeit few 
in number, have consistently found that many, if not most DMST victims, prior to being trafficked experienced child physical abuse (Ashley, 2008; OJJDP, 2002; Spangenberg, 2001; Smith et al., 2009), psychological abuse (OJJDP, 2002; Spangenberg, 2001), repeated abuse or neglect (Ashley, 2008; Boxill \& Richardson, 2007; OJJDP, 2002), and had a history of sexual abuse (Ashley, 2008; Boxill \& Richardson, 2007; Clawson et al., 2009; OJJDP, 2002). In a study of 361 female homeless and runaway youth, Tyler, Hoyt, and Whitbeck (2000) found that early sexual abuse in the home had both direct and indirect effects on later sexual victimization once on the streets.

Many youth also come from a dysfunctional home (Ashley, 2008), or one characterized by poor family functioning (Boxill \& Richardson, 2007), family disruption (Clawson et al., 2009), or parental substance abuse and violence (OJJDP, 2002; Smith et al., 2009). Youth under these conditions often experience poor school performance or school-related problems (Ashley, 2008; Boxill \& Richardson, 2007; Clawson et al, 2009) and are chronic runaways with periods of homelessness (Ashley, 2008; Clawson et al., 2009; OJJDP, 2002).

A recent national study of juvenile prostitution incidents known to law enforcement found that $60 \%$ of youth had a history of running away (Mitchell et al., 2010). Once on the streets, many runaway or homeless youth engage in survival sex to fulfill their basic needs (Ashley, 2008; Spangenberg, 2001). Several studies cite that approximately one-third of youth are lured into prostitution or solicited for sex within 48 hours of being on the streets after leaving home (Clayton, 1996, as cited in Spangenberg, 2001; National Runaway Switchboard, as cited in Ashley, 2008). Moreover, there is 
general consistency that the average age of entry into prostitution is between 11 and 14 (Ashley, 2008; Clawson et al., 2009; Leitch \& Snow, 2010; Smith et al., 2009; Spangenberg, 2001).

However, not all confirmed DMST victims are runaways or homeless youth. Contrary to the findings of other researchers, in their national study of juvenile prostitution, Mitchell et al. (2010) found that a majority of the juveniles engaged in prostitution were not homeless. Smith et al. (2009), in their collaborative research with ten USDOJ funded human trafficking taskforces across the U.S., found that many DMST victims were previously involved in the child welfare system with a history of Child Protective Services (CPS) involvement. They even identified out-of-home CPS placements to be a source for DMST recruitment.

Boxill and Richardson (2007) found that a majority of girls who had been identified as victims of prostitution in Atlanta were lured or kidnapped from schools, bus stops, malls, and movie theaters, a finding consistent with Smith et al. (2009). A 2002 study by the OJJDP found that pimps procured juveniles by frequenting "areas where juveniles [were] apt to congregate such as shopping malls, videogame arcades, and bus stations" (p. 1). For documented cases of child pornography, victims were sought out in unethical modeling agencies, under-21 clubs, juice bars, and fast-food establishments (OJJDP, 2002). In such places, pimps feign friendship and love, use a combination of intimidation and seduction, and target and then profess to fulfill an identified unmet need of the targeted youth (OJJDP, 2002; Smith et al., 2009). It is important to note however, that not all youth engaged in prostitution are under the control of a pimp or third-party 
exploiter (Mitchell et al., 2010). Both official data and research studies continue to support the finding that a portion of juveniles engaged in prostitution do so under their own volition (Curtis, Terry, Dank, Dombrowski, \& Khan, 2008; Finkelhor \& Ormrod, 2004; Green et al., 1999; Mitchell et al., 2010)

Victims come from a variety of socio-economic backgrounds, races, and ethnicities (Smith et al., 2009; Spangenberg 2001) and often mirror the demographic characteristics of the local community (Boxill \& Richardson, 2007). In their investigation into the lives of victims at ages 9 to 11 prior to their victimization, Boxill and Richardson (2007) found that the girls "would have been difficult to distinguish from those in your family album" (p.142). Despite the possibility that seemingly any youth, especially those in custody settings, could be a victim of DMST, Smith et al. (2009) identified the most common red flags to be homelessness, chronic running away (three or more times), having an older boyfriend, tattoos or brands, access to material goods that the youth would not be able to afford, physical signs of trauma or violence, delinquency charges (a.k.a. masking charges) such as loitering, curfew violations, or other status offenses, and being accompanied by an older male who is not a guardian.

\section{Third Party Exploitation}

Complicating matters of identification stem from the relationship between the youth and the pimp when one is involved. Work by Spangenberg (2001) found that while prostituted boys often worked on their own, most girls were under the control of a pimp, a finding supported by Finkelhor and Ormrod (2004). The tactics used by pimps mirror those of power and control used by batterers in domestic violence (Smith et al., 2009). 
Social isolation, economic dependency, intimidation, control, and other power coercive tactics make leaving the life of prostitution extremely difficult (Ashley, 2008).

Pimps may be a boyfriend, relative, or even a parent (Ashley, 2008). When the pimp is either a relative or a parent, it is considered familial trafficking. Smith et al. (2009) found familial trafficking to be associated with "the existence of a drug-addicted parent" and occurs "when a family member trades or rents their child for sexual use by another in exchange for money, food, drugs, etc." (p. 32). When youth are the victims of familial trafficking, they "do not aid in investigations because it is their only means, or their family's only means, of survival" (Ashley, 2008, p. 3).

In general though, victims of commercial sexual exploitation either do not, or are unable to, self-identify (Leitch \& Snow, 2010; Smith, et al., 2009). Reasons include denial, fear of law enforcement, and fear of retaliation by a trafficker/pimp (Stolz, 2010; Weiner \& Hala, 2008). In addition, trauma bonds often form between the juvenile and the pimp, resulting in the juvenile perceiving the pimp to be a boyfriend (OJJDP, 2002; Smith et al., 2009). In this situation, trauma bonding manifests itself as the love that juveniles come to associate with their pimp and has parallels to Stockholm Syndrome. "Psychologically these women develop strategies to justify, minimize, and create illusions of control, choice, and purpose" in order to rationalize their situation (OJJDP, 2002, p. 15). Ashley (2008) found that most youth do not see themselves as victims, or have convinced themselves that prostitution is their choice and their "pimp is the only one who will love and protect them" (p. 6). 


\section{Summary}

Taken together, qualitative research has identified three principle ways that youth are procured for sexual exploitation: 1) runaway/thrownaway who are solicited or recruited for prostitution (Clayton, 1996, as cited in Spangenberg, 2001, p. 8; Cohen, 2006, as cited in Ashley, 2008; National Runaway Switchboard, as cited in Ashley, 2008, p. 7; Smith et al., 2009); 2) youth tricked, lured, or kidnapped (Ashley, 2008; Boxill \& Richardson, 2007; OJJDP, 2002; Smith et al., 2009); and 3) youth who are exploited by their own family (Ashley, 2008; Smith et al., 2009). It is therefore important to develop measures that are flexible and sensitive to the various ways that youth become sexually exploited. Prior research is consistent in finding that DMST victims are frequently runaways (Ashley, 2008; Clawson et al., 2009; OJJDP, 2002; Smith et al., 2009) who have experienced prior abuse (Ashley, 2008; Boxill \& Richardson, 2007; Clawson et al., 2009; OJJDP, 2002; Smith et al., 2009; Spangenberg, 2001). Unfortunately, such correlates also mirror those of juvenile delinquency in general and do not, in-and-of themselves, indicate DMST victimization even though they may increase the likelihood or risk of victimization. 


\section{The Current Study}

The sexual exploitation of children exists on a continuum with domestic minor sex trafficking (DMST) being the most severe and extreme form. Qualitative research has shed light on how youth are procured for sexual exploitation, the nature and types of sexual exploitation youth experience, and risk factors that increase the likelihood of sexual victimization. To date, however, there has been no quantitative attempt to identify victims in a methodical way in order to determine either the prevalence of DMST at a local level or the nature and strengths of its correlates. Complicating matters of identifying victims is that they are often arrested for masking charges and either do not, or are unable to, self-identify. As a result, these youth are never recognized as victims and subsequently do not get the treatment and help they need.

The present study is the first of its kind to attempt to systematically identify victims of DMST in a juvenile custody setting. All youth taken into custody over a three and a half month period at the Clark County Juvenile Detention Center in Vancouver, WA received a short assessment as part of their standardized intake process in order to strategically identify those most at risk of victimization and in need of additional screening. The process consisted of a three-tiered screening approach, with each tier progressing in level of question invasiveness. The expectation was that such a process would increase the timely and accurate identification of victims in order to divert them from the formal juvenile justice system and link them to appropriate social, mental, and health services in the community. 
To this end, the current study examines whether a Response Team, comprised of detention and probation staff, identified the presence of DMST risk factors in youth screen interviews, that prior research suggests are associated with DMST victims. The expectation is that the initial screen interview will uncover the presence of certain risk factors and assist detention and probation staff in identifying youth who are in need of additional in-depth assessment to determine their DMST status. Significant differences between youth who were referred for additional assessment and those who were not will indicate that detention and probation staff were making referral decisions based on the presence of DMST risk factors. A qualitative analysis is also provided of the presence of risk factors, or lack thereof, of youth confirmed as victims during the course of the study. Approach

Shared Hope International, in partnership with "a multidisciplinary committee of experts in the field of service provision to DMST victims", developed and validated a "practitioner's training guide and intake tool specific to the identification of potential or current child/adolescent victims of sex trafficking" for youth aged 12-20 (Leitch \& Snow, p. 1 \& 19). The intake tool is comprised of two interview tiers (Tiers 1 and 2) modeled after a strengths-based and trauma-informed approach. The approach "attempts to reorganize invasive questions into an empowerment memory framework...[while] inserting positive and less invasive questions within a disclosure" (Leitch \& Snow, p. 19 \& 20). The challenge posed by Shared Hope's intake tool for this study is that it was not designed for, and had never been used in, a custody setting. 
Screening youth in a juvenile custody setting requires additional considerations of resources, capacity, the physical environment, and youth's state of mind. While a strengths-based and trauma-informed approach may be preferable in social service settings, the length of time Shared Hope's Intervene tool takes to complete was not practical or feasible in this case. In addition to the time commitment (i.e. staff resources), the environment and who would be administering the assessment also had to be considered. Youth who come into juvenile detention may be under the influence of drugs and are often highly agitated or emotional. In addition, there is very little privacy during the intake process and multiple youth may be processed at the same time by different detention officers. This factor alone limits the types of questions that youth would truthfully and/or even be willing to answer. More importantly though, as Shared Hope's tool was designed to facilitate disclosure of victimization, the detention intake environment was not deemed to be suitable or appropriate for such sensitive and confidential issues. Further complicating matters is how Clark County Juvenile Detention does not have a dedicated intake staff. As a result, many detention officers who are not specifically and/or sufficiently trained in DMST or trauma-informed approaches conduct intakes.

In light of such circumstances, a modified screening instrument was developed by Dr. Emily J. Salisbury and Kelli Russell at Portland State University. One of the key considerations was to develop an instrument in line with the reality that intake officers are first and foremost detention officers, not social workers, counselors, advocates, or mental health professionals. Secondly, the assessment needed to be short, to the point, 
and relatively non-invasive. What resulted was a new screening interview in conjunction with Share Hope's two-tiered intensive interview. Shared Hope's Tiers 1 and 2 were subsequently utilized as Tiers 2 and 3 . The new Tier 1 was incorporated into the juvenile detention standardized intake process and administered to all youth taken into custody. 


\section{Sample}

\section{Methods}

Data for this study consisted of a cohort sample of all youth entering the Clark County Juvenile Detention Center in Vancouver, WA beginning October 11, 2010 and ending January 31, 2011. A total of 535 youth ages 9 to 19 were screened with a brief instrument developed to assess DMST risk factors. Youth identified as having certain risk factors were subsequently referred for additional screening. Demographic characteristics of the 535 youth were obtained from the Clark County Juvenile Court System (JCS) database and are provided in Table 1. Of the 535 total youth, a majority were White (76.2\%), male (71.4\%), and between the ages of 15 to $17(74.1 \%)$.

\section{Instruments}

Tier 1. The "Tier One Detention Screening Interview" consisted of 14 interview questions and 18 line items (see Appendix A). Four interview questions assessed where each youth lived, with whom, and if they currently slept there. Information obtained from these questions was used to create a dichotomous variable indicating "living situation risk". Youth deemed to have living situation risk included those who were homeless, transient, currently on the run, or not sleeping at home consistently. Two questions assessed youth runaway history and one question assessed if youth had ever been in foster care. In addition, a line item completed by the Tier 1 interviewer indicated whether CPS/DSHS was currently involved with the youth. Four questions assessed the youth's prior contacts with law enforcement, one of which asked the youth what cities their police contacts occurred in. From this question, new variables were created to 
assess if the youth reported any contacts outside of Clark County, WA, any contacts in a state other than Washington, any contacts in Oregon, and any contacts in Portland, OR. Additional staff observation line items completed by the Tier 1 interviewer indicated whether the youth had any visible brands or tattoos, any evidence of abuse (ligature marks, burns, bruises, etc.), and any personal property items of concern (i.e. hotel keys, large amounts of cash, Viagra pills, condoms, etc.). At the end of the Tier 1 interview, the interviewer was asked to indicate whether the youth was a "self-disclosed victim", "non-disclosed; suspected victim", or "non-disclosed; not suspected".

Tier 2. Tier 2 represented Shared Hope's Tier 1 instrument as found in their publication "Intervene: Identifying and Responding to America's Prostituted Youth" (see Appendix B). The interview consisted of 34 questions exploring runaway/homelessness, traveling/transportation, delinquency, relationships, and tattooing. Prior to administering the Tier 2, youth were given an assent form explaining that their answers may be used in a research study if they wished to participate. Tier 2 and the assent form were administered by special detention and probation staff who comprised a Response Team. The time it took to administer Tier 2 ranged from 5 to 45 minutes depending on the youth's level of cooperation and types of risk factors identified. Over the three and a half month period of research, a total of 47 youth were referred to a Tier 2 interview. Five youth referred to Tier 2 were released from custody prior to being able to receive it. Two youth referred to Tier 2 refused participation in the interview. An additional two youth participated in the Tier 2 interview but refused to sign the assent form which was 
required in order to use the data for the study. In all, 36 youth both signed the assent form and participated in the Tier 2 interview representing a response rate of $76.6 \%$.

Tier 3. Tier 3 reflected Shared Hope's Tier 2 instrument as found in their publication "Intervene: Identifying and Responding to America's Prostituted Youth" (see Appendix C). The interview consisted of 46 questions that more deeply explored the youth's living situation, relationship with parents, runaway history, traveling, sources of and control over money, and partner history including physical and sexual assault. Tier 3 was administered by victim advocates from both the YWCA and Sexual Assault Resource Center (SARC). Over the three and a half month period of research, 11 youth were referred to a Tier 3 interview of whom all participated.

Juvenile Court System (JCS) Data.

JCS is one of several databases used in Washington to track juveniles and their court cases across the state. Demographic information, criminal histories, and nonoffender referrals were recorded from JCS for each Tier 1 that was completed. Youth's race was recorded on all Tier 1's by detention intake officers based on their own perceptions of the youth's physical features. As a result, these data may not be an accurate reflection of the racial distribution of the sample. Thus, the decision was made to use race as it was recorded in the JCS database. For the purposes of analysis, youth's race was collapsed and coded as Hispanic if there was any indication that the youth was Hispanic. This included Hispanic-Whites, Hispanic-Non-Whites, and HispanicUnknown. 


\section{Procedures}

During the months leading up to and throughout the course of the study, several meetings and training sessions took place involving research and juvenile detention and probation staff. One such training was facilitated by Shared Hope International. A mandatory in-service training was also held at the Clark County Juvenile Court. Staff representing all levels of both the juvenile probation department and juvenile court, including senior management, were in attendance. The training provided a brief overview of DMST and explained the intake screening tool (Tier 1; see Appendix A) that was to be used by juvenile detention staff. The training also covered staff responsibilities in the event of a disclosure. A subsequent training was conducted for specific detention and probation staff who comprised a Response Team. Members of the Response Team were previously trained in DMST and were responsible for reviewing the completed Tier 1 's for risk factors, making the determination of whether to refer the youth to Tier 2 , and actually conducting the Tier 2 interview with the youth.

In addition to identifying potential victims of DMST, administrative policies and procedures were developed by the Clark County Juvenile Court to establish what to do if and when a youth disclosed victimization. Such policies included, but were not limited to, mandatory reporting to Child Protective Services, DNA and sexual assault kit timelines, notification to local law enforcement, the FBI, and victim advocates. Great lengths were taken by the Clark County Juvenile Court to establish a multidisciplinary team in order to ensure that youth who disclosed victimization received any necessary treatment, services, and referrals. 
All youth entering Clark County Juvenile Detention were screened with the Tier 1 screening instrument beginning October 11,2010. Youth typically arrived in detention one of three ways: (1) brought in by an arresting agency, (2) taken into custody following court, or (3) turning themselves in. All three circumstances resulted in the same standardized intake procedure. Upon arriving in detention, youth were processed out in the open at a counter designed to accommodate more than one youth intake at a time.

The intake process began with the detention officer completing a Clark County Juvenile Court Detention Risk Assessment to determine whether the youth qualified to be held in detention. Regardless of the decision to hold the youth, the intake officer then completed an intake report which updates and/or confirms the youth's demographic, home, school, and guardian information, basis for detention, and detention hold or release actions taken. Following these two steps, each and every youth received a "Tier One Detention Screening Interview" which contained 14 interview questions and an additional 18 observation fields completed by the intake officer (see Appendix A). Officers were provided with the option to complete Tier 1 either electronically or by hand. At this point, the intake process was complete for youth who qualified for release. Youth who were being held continued on with the intake process.

Once per day, a Response Team member from the Clark County Juvenile Court reviewed all Tier 1's completed during the preceding 24-hour period to determine whether any youth needed additional screening for DMST. The goal was to have Tier 2 interviews completed within 24 hours of Tier 1 . To assist in this decision, at the bottom of each Tier 1 form, the Tier 1 interviewer was instructed to indicate whether the youth is 
a "self-disclosed victim", "non-disclosed; suspected victim", or "non-disclosed; not suspected". Youth who were deemed to be at risk, either by the Tier 1 interviewer, Response Team member, or both, were subsequently referred to a Tier 2 interview (Shared Hope's Tier 1 instrument, see Appendix B). Prior to administering Tier 2, the Response Team member reviewed an assent form with the youth. As minors, juveniles are not able to give legal consent. A copy of the assent form can be found in Appendix D. Per Portland State University's Human Subjects Research Review Committee (HSRRC), data from Tiers 2 and 3 could only be collected by research staff for youth who had signed an assent form. The assent form was not required until Tier 2 because Tier 1 was not designed to facilitate DMST disclosure.

Youth who remained "non-disclosed; suspected victim" following their Tier 2 interview were subsequently referred for a Tier 3 interview. Tier 3 interviews (Shared Hope's Tier 2 instrument, see Appendix C) were conducted in a private interview room in juvenile detention by trained advocates from both the YWCA in Vancouver, WA and the Sexual Assault Resource Center (SARC) in Portland, OR. The decision to have trained victim advocates administer the interview was made in part due to practical and resource constraints, but primarily because these questions were most invasive and intrusive. To this end, Shared Hope cautions that the final screening tool "should only be used by trained and/or licensed professionals who must have an understanding of trauma and DMST" (Intervene, p. 21). 


\section{Analysis}

Phase one of the analysis used Chi-square and bivariate correlations to examine the differences between youth who were referred to a Tier 2 interview and those who were not across certain variables. The purpose of this analysis was to determine the extent to which detention and probation staff identified the presence of DMST risk factors in youth Tier 1 screen interviews. The types of variables, including the dichotomous nature of the dependent variable (whether or not the youth was referred to a Tier 2) limited the types of analysis that could be performed. Phase two of the analysis qualitatively examined the individual characteristics, Tier 1 interviews, and criminal histories of youth confirmed as DMST victims during the research process. The low number of confirmed victims limited the types of analysis that could be performed as there were not enough cases to reach statistical power.

Over the course of three and a half months, 738 Tier 1's were conducted representing a total of 535 youth. As was to be expected, many youth were processed through detention more than once (27.3\%), resulting in more than one Tier 1 interview for certain youth. The decision was made to include in the analysis the Tier 1's of youth who had multiple intakes because many of the risk factors assessed by the interview are dynamic and change. Unlike demographic characteristics which are static, a youth's living situation, runaway status, foster care placement, travel patterns, and DMST status are likely to change over the course of weeks and months. An examination of cases that resulted in a Tier 2 reveals that 7 youth (19.4\%) who received a Tier 2 did not receive it until the second time they were detained. It must be noted however, that some of these 
youth were identified as needing a Tier 2 the first time they were detained but were unable to receive it due to being released from custody.

Additionally, the decision was made to exclude a number of Tier 1 interviews from the analysis: youth who were already confirmed as victims prior to the study $(n=$ 4), subsequent Tier 1's of youth confirmed as victims during the study $(n=6)$, and subsequent Tier 1's of youth who received a Tier $2(n=17)$. The purpose of Tier 1 was to screen youth for DMST risk factors in order to strategically identify only those in need of additional screening. The purpose of Tiers 2 and 3 were to determine whether or not the youth was a DMST victim. As a result, youth who were confirmed or known victims did not qualify for any additional screening following their identification as they were already identified as such and referred for services. Furthermore, it was felt that additional screening posed the risk of re-traumatizing these youth. Along the same lines, youth who received a Tier 2 and were subsequently deemed "non-disclosed; not suspected" were not later referred to Tier 2 again because they were already identified as non-victims. Because all of the above mentioned youth had a known DMST status, it was deemed necessary to exclude their subsequent Tier 1 interviews $(N=27)$ from the analysis as each youth was not referred again to Tier 2 following any subsequent detentions, despite what risk factors their Tier 1's indicated. 


\section{Results}

A total of 738 Tier 1 interviews were completed during the course of the study representing 535 total youth. Demographic characteristics of the cohort sample are provided in Table 1. Many youth entered detention more than once (27.3\%). Tier 1 frequencies are presented in Table 2 . Only three youth had a prior charge for prostitution in JCS ( 1 female; 2 male). The female was a confirmed DMST victim prior to the research process. The two males were not referred to either a Tier 2 or 3 and their DMST status is unknown. Forty-seven youth (8.8\%) were referred to a Tier 2 interview, of whom 36 youth received one. Five youth referred to a Tier 2 did not receive one due to being released and four youth refused participation. Every effort was made to determine what happened in the other two cases but it remains unknown. It is possible that the two youth were referred to a Tier 2 and the referral decision was subsequently overridden, however this cannot be confirmed. Demographic characteristics of the 47 youth referred to a Tier 2 are provided in Table 3.

\section{Youth Referred to Tier 2}

During the course of the study, 47 youth $(8.8 \%)$ were referred to a Tier 2 interview. Demographic characteristics are provided in Table 3. A majority were female (72.3\%), White (83.0\%), and had previously run away from home (89.4\%). A good

portion of the youth were currently on the run or not sleeping at home consistently (33.3\%), had previously been in foster care (42.6\%), were currently involved with CPS/DSHS (47.7\%), reported police contacts outside of Clark County, WA (37.2\%), and had visual evidence of brands/tattoos $(25.0 \%)$. 
Two-way contingency table analyses were conducted to evaluate whether certain risk factors were related to a youth being referred to a Tier 2 . All variables were dichotomous and dummy variables were created so that " 0 " indicated the absence of a risk factor and "1" equaled the presence. Conventionally, Phi coefficients are used to report effect sizes in Chi-square analyses using nominal level variables. While the Chisquare statistic indicates whether there is a statistically significant difference between groups, it does not indicate direction and is not easily interpretable on its own. The decision was made to report the Pearson's Correlation Coefficient $(r)$ in place of Phi to indicate the strength of the bivariate relationships and ease the interpretation of the findings. It should be noted however, that Pearson's $r$ values were identical to the Phi coefficients for every variable analyzed.

Gender, along with the nine DMST risk factors examined, were found to be significantly related to a youth being referred to Tier 2. Chi-square and Pearson's $r$ values for Tier 1 variables are reported in Table 4 . While females comprised $25.8 \%$ of the cohort sample, they comprised $72.3 \%$ of those referred to Tier $2, \chi^{2}(1, N=708)=$ $56.78, p<.001, r=.283$. Youth who were currently on the run or not sleeping at home represented $9.3 \%$ of the cohort sample but comprised $33.3 \%$ of those referred to Tier 2 , $\chi^{2}(1, N=474)=24.36, p<.001, r=.227$. Youth who reported having run away from home at least once represented $39.9 \%$ of the cohort sample, yet they comprised $89.4 \%$ of those referred to Tier $2, \chi^{2}(1, N=710)=51.45, p<.001, r=.269$. Youth currently involved with either CPS or DSHS represented $12.7 \%$ of the cohort sample compared to $47.7 \%$ of those referred to Tier $2, \chi^{2}(1, N=679)=52.29, p<.001, r=.278$. Statistically 
significant differences were also found for prior foster care placement, having prior law enforcement contacts both outside of Clark County and in a state other than Washington, visual evidence of brands/tattoos, and evidence of abuse. These results suggest that detention and probation staff identified the presence of DMST risk factors in youth screen interviews and were making referral decisions based on the presence of those risk factors.

Tier 1 interviewers only indicated a DMST disclosure status for 447 Tier 1 interviews (60.6\%) of which $96.2 \%$ were marked as "non-disclosed; not suspected". In order to determine whether the referral process to Tier 2 was successful, the relationship between the youth's DMST status as perceived by the Tier 1 interviewer and the referral decision by the Response Team member was examined. A positive relationship was found indicating that youth deemed "non-disclosed; suspected victim" by the Tier 1 interviewer were significantly more likely to be referred to a Tier 2 by a Response Team member $(r=.431, p<.01)$.

Thirty-six youth actually received a Tier 2 interview. As a result of Tier 2, five youth disclosed DMST victimization, five remained "non-disclosed; suspected victim", 13 were deemed "non-disclosed; not-suspected", and 13 did not indicate a disclosure status. Of the 36 youth who received a Tier 2, $11(30.6 \%)$ went on to receive a Tier 3 interview. The remaining confirmed victim disclosed victimization at some other point in the process. 


\section{Confirmed Victims}

Six youth were identified and confirmed as DMST victims during the course of the study. A comparison of their Tier 1 characteristics can be found in Table 5. A comparison of their official data can be found in Table 6. All six victims were female, between the ages of 14 to 17 , and had histories of running away. A majority were White $(83.3 \%)$, were in detention for a probation violation and/or warrant $(83.3 \%)$, had between 4 and 6 court cases on file (83.3\%), and were currently involved with CPS/DSHS $(66.7 \%)$. Half of the youth had one or more truancy petition on file, were not originally from Washington, had previously been in foster care, had visual evidence of tattoos, and did not report any law enforcement contacts outside of Clark County.

Below are Tier 1 characteristics and official data of youth confirmed as DMST victims during the course of the study $(n=6)$. The information reported corresponds to the Tier 1 that was associated with the youth's confirmation and risk factors assessed. Additional JCS data are also provided.

Case \# 1 is a 14 year old, White female. During the course of the study, she came through detention twice, once in October and once in November. Her Tier 1 in October indicated that she was kicked out of her home, was not living anywhere, had run away more than six times, had previously been in foster care, did not have anyone who takes care of her when she needs help, police contacts in both Vancouver, WA and Idaho, visual evidence of tattoos ("three dots on her left hand"), and CPS/DSHS was currently involved with her. Her Tier 1 did not indicate the possession of any personal property items of concern, evidence of abuse, or gang affiliation. Her Tier 1 interviewer marked 
her disclosure status as "non-disclosed; not suspected". Despite this conclusion by the Tier 1 interviewer, a Tier 2 Response Team member referred her to Tier 2 during which she disclosed both familial trafficking and being pimped. Case \#1 was in custody for a p.v. and/or warrant, had 3 prior warrants, 5 prior probation violations, 5 court cases on file, 1 truancy petition, and was currently living with foster parents. Prior to her disclosure, she had been in detention 8 times and had served 46 days in custody.

Case \# 2 is a 17 year old female of an unknown race/ethnicity. During the course of the study, she came through detention three times, once in October, once in November, and once in January. Her Tier 1 in October indicated that she was currently living in foster care, had run away from home approximately 10 times, CPS/DSHS was currently involved with her, and she was high on methamphetamine during intake. Her Tier 1 did not indicate police contacts outside of Vancouver, WA, the possession of any personal property items of concern, any evidence of brands, tattoos, abuse, or gang affiliation. Her Tier 1 interviewer did not indicate a disclosure status, but she was referred to Tier 2 by a Response Team member during which she disclosed being pimped and engaging in survival sex. Case \# 2 was in custody for a p.v. and/or warrant, had 2 prior warrants, 2 prior probation violations, 7 court cases on file, 1 truancy petition, 1 dependency petition, and 1 child in need of services (CHINS) petition. Prior to her disclosure, she had been in detention 8 times and had served 62 days in custody.

Case \# 3 is a 15 year old, White female. During the course of the study, she came through detention twice, once in October and once in November. The only risk factor identified in her Tier 1 in October was that she had run away from home approximately 3 
times. She was currently living at home and had never been in foster care. Her Tier 1 did not indicate police contacts outside of Vancouver, WA, the possession of any personal property items of concern, any evidence of brands, tattoos, abuse, gang affiliation, or whether CPS/DSHS was currently involved. Her Tier 1 interviewer in October did not indicate a disclosure status, but she was referred to Tier 2 by a Response Team member which leads to speculation as to why she was referred. During her Tier 2 interview, she disclosed engaging in prostitution. Case \# 3 was in custody for a p.v. and/or warrant, had 1 prior warrant, 2 prior probation violations, 4 court cases on file, and 1 truancy petition. She was also listed in the JCS database as having a tattoo/scar of "C" "B" on her right wrist. Prior to her disclosure, she had been in detention 7 times and had served 51 days in custody.

Case \# 4 is a 14 year old, White female. During the course of the study, she came through detention four times, once in November, once in December, and twice in January. Her Tier 1 in November indicated that she was now living back at home, had run away approximately 4 times, had previously been in foster care, and CPS/DSHS was currently involved with her. Her Tier 1 did not indicate police contacts outside of Vancouver, WA, the possession of any personal property items of concern, any evidence of brands, tattoos, abuse, or gang affiliation. Her Tier 1 interviewer indicated that she was a "self-disclosed victim". A Response Team member did not refer this youth to a Tier 2 until her second Tier 1 in December for unknown reasons. The story uncovered behind Case \# 4 is that she had voluntarily gotten into a stranger's car while waiting at a bus stop during which time she was kidnapped and pimped across multiple states over a 
period of several months. Case \# 4 was in custody for a p.v. and/or warrant, had 4 prior warrants, 4 prior probation violations, 5 court cases on file, and no prior non-offender referrals/petitions. Prior to her disclosure, she had been in detention 8 times and had served 53 days in custody.

Case \# 5 is a 14 year old, White female. During the course of the study, she came through detention once in November. Her Tier 1 indicated that she was not living anywhere in particular, had run away from home more than 10 times, had prior police contacts in Vancouver, WA, Battleground, WA, and Portland, OR, had visual evidence of tattoos, visual evidence of abuse (bruises on her arms), and CPS/DSHS was currently involved with her. Her Tier 1 did not indicate any prior foster care placement, the possession of any personal property items of concern, or gang affiliation. Her Tier 1 interviewer marked her disclosure status as "non-disclosed; suspected victim". She was referred by a Response Team member for a Tier 2 during which she disclosed having a pimp. Case \# 5 was in custody for a p.v. and/or warrant, had 4 prior warrants, 6 prior probation violations, 5 court cases on file, and no prior non-offender referrals/petitions. Prior to her disclosure, she had been in detention 8 times and had served 74 days in custody.

Case \# 6 is a 15 year old, White female. During the course of the study, she came through detention twice, once in October and once in January. Her Tier 1 in January indicated that she had run away approximately 6 times and had tattoos on both wrists "Smile Now" "Cry Later". Her Tier 1 did not indicate police contacts outside of Vancouver, WA, any prior foster care placement, the possession of any personal property 
items of concern, any evidence of brands or abuse, gang affiliation, or CPS/DSHS involvement. Her Tier 1 interviewer marked her disclosure status as "non-disclosed; not suspected". Despite this conclusion, she was referred to a Tier 2 by a Response Team member during which she was very evasive and did not disclose. Shortly after her Tier 2 interview, she was implicated by another youth in custody which resulted in a referral to the FBI and her disclosing having a pimp. Case \# 6 was in custody for a new charge of Theft 3, had 3 prior warrants, 3 prior probation violations, 5 court cases on file, and no prior non-offender referrals/petitions. Prior to her disclosure, she had been in detention 5 times and had served 39 days in custody. 


\section{Discussion}

The present study was the first of its kind to attempt to systematically identify, first hand, DMST victims in custody in a methodical way in order to determine prevalence at a local level. All youth detained at the Clark County Juvenile Detention Center received a short assessment designed to identify those most at risk of victimization and in need of additional screening. The results suggest that detention and probation staff generally identified the presence of DMST risk factors as assessed by youth screen interviews and were making referral decisions based on the presence of those risk factors. Prior to the study, 17 victims of DMST were identified and confirmed by the Clark County Juvenile Court. As a result of this study, six additional victims were identified. Including four of the known victims who came through detention, DMST youth represented $6.6 \%$ of girls and $1.9 \%$ of all youth taken into custody over the three and a half month period.

The study specifically examined risk factors associated with DMST both among youth who were identified as 'at risk' and victims confirmed during the research process. Overall, the results support the need for a tiered screening process with checks and balances to identify victims of DMST in a juvenile custody setting. A thorough, in-depth assessment of all youth taken into custody for DMST victimization would be too time intensive, unnecessary, and likely unreliable given the lack of privacy, youth's state of mind, and who administers the interview.

The present study used a brief Tier 1 screen interview to assess youth for risk

factors in order to identify only those youth at greater risk of victimization. Tier 1 was 
intentionally designed to be short, relatively non-invasive, and not facilitate any type of victimization disclosure because the detention officers administering the interview were not sufficiently trained in either DMST or trauma-informed approaches.

Youth identified as at greater risk through their Tier 1 screen interview were referred to a Tier 2 interview, developed by Shared Hope, which was designed to facilitate disclosure of victimization. To this end, five of the six DMST victims confirmed during the study disclosed their victimization during the Tier 2 interview. This supports the decision to use Shared Hope's Intervene Tool as a secondary assessment, administered by members of a Response Team specifically trained in DMST, rather than as a primary assessment incorporated into the intake process.

To aid in the referral decision, Tier 1 interviewers were instructed to indicate whether they perceived the youth to be "non-disclosed; not suspected" or a "nondisclosed; suspected victim" at the end of each assessment. An examination of this decision revealed not only that Tier 1 interviewers left this line item blank on $37.1 \%$ of interviews, but at times their assessment was flawed. To this end, of the six victims referred to a Tier 2 and subsequently confirmed during the study, two did not have a DMST status indicated on their Tier 1 and two were deemed "non-disclosed; notsuspected" by their Tier 1 interviewer. Overall, $65.4 \%$ of youth referred to Tier 2 by a Response Team member were rated as "non-disclosed; not suspected" by their Tier 1 interviewer. Clearly, Response Team members, with the additional DMST training they received, were able to make better referral decisions based on known risk factors associated with DMST. Had this system of checks and balances not been in place, 
several victims would likely not have received the additional in-depth assessments that identified them.

Taken together as a group, the DMST victims confirmed during the study had risk factors consistent with prior research: All had runaway histories and multiple court cases on file, a majority were currently involved with CPS/DSHS, and half had prior nonoffender referrals, previous foster care placement, and brands/tattoos. Most original DMST and CSEC studies are case studies, qualitative, and focus on the nature and types of victimization that youth experience. Consequently, very little is quantified with regards to the prevalence of risk factors and commonalities among identified victims as assessed by this particular study. As a result, the extent to which the findings of this study are consistent with prior research cannot be determined with absolute certainty.

In examining the characteristics of confirmed victims, a considerable amount of variation was found among specific risk factors. Aside from all youth being female with prior runaway and criminal histories, no definitive pattern emerged. Further complicating matters is how the same risk factors were found within the cohort sample in general. Certainly, it is a possibility that some DMST victims were missed in the process. However, the proportion of false negatives cannot be determined.

Several limitations must be noted with regard to the findings. According to the 2009 Washington State Juvenile Justice Annual Report, in 2008, Clark County had 2,106 juvenile admissions to its detention facility. Of those youth, $74.4 \%$ were male and $78.5 \%$ were White. Unfortunately, the figures reported in the annual report only represent youth who were held in detention for at least four hours. Youth who were screened and 
subsequently released were not reflected in the report. In the present study, all youth, including those who were screened and released, were given a Tier 1 interview and captured in the data set. Over the course of three and a half months, there were a total of 738 youth admissions ( $71.0 \%$ male, $72.9 \%$ White). Screen and release was not recorded as a data point until midway through the study. As a result, it is not possible to determine the percentage of youth who remained in custody for at least four hours in order to compare the number of admissions and demographic characteristics of our sample for purposes of generalizability. While the gender and racial distribution of the cohort sample is similar to that found in the annual report, slight differences do exist.

Second, although an examination of the referral process to Tier 2 revealed a moderate positive relationship $(r=.431, p<.01)$ between the Tier 1 interviewers' assessment and the Response Team members' decision to refer the youth to Tier 2, a stronger correlation is desirable. Of the 47 youth referred to Tier 2 by a Response Team member, 65.4\% were rated as "non-disclosed; not suspected" by their Tier 1 interviewer. This may in part be a reflection of the additional DMST training that Response Team members received compared to regular detention officers. It is also possible that Response Team members used additional criteria, such as prior knowledge of the youth or conversations overheard in the housing pods, in their referral decisions above and beyond the risk factors identified within the Tier 1 interview. Nevertheless, given that this project represented a brand new procedure in detention, the statistically significant agreement between Tier 1 and 2 interviewers suggests some level of success in the identification process. 
As with any new intervention, the study encountered some problems with organizational and staff implementation. First, throughout the study, significant intraagency conflicts contributed to some staff refusing to accept the goals of the research and to thus contribute to its success. An examination of the data revealed that certain staff were more committed to the process than others. Second, some lack of accountability of staff from administrative personnel impeded a more successful implementation. For example, prior to the study, a mandatory in-service training was held for all juvenile detention and probation staff. Unfortunately, not all detention officers who ended up conducting Tier 1 interviews were in attendance. Several requests were made to hold an additional training for these staff but were subsequently ignored or denied by mid-level management. One month into the study, requests were made to hold a meeting with the staff conducting Tier 1 interviews to solicit feedback regarding any issues concerning either the process or screening instrument in order to identify and make any necessary adjustments. Unfortunately, issues with implementation ultimately had to be addressed through a single mass email distributed to staff and very little feedback was received. Yet, despite the organizational obstacles, Clark County Juvenile Court is strongly commended for being open enough as an agency to pilot an innovative strategy to identify victims they suspect within their custody. Many criminal justice agencies would rather deny such a problem, allowing it to persist, in order to protect themselves from outside researchers. Moreover, implementing a new process that requires a normative reorientation of traditional values is challenging for any organization to achieve. 
Third, relatively few victims were identified and confirmed during the course of the study. It may be tempting to interpret the findings to suggest that DMST is not as prevalent as certain sources claim it to be. However, a portion of youth deemed at risk and subsequently referred to Tier 2 did not receive one because they were released from custody and did not later return during the study. As a result, it is possible that a small number of victims were not identified. On the other hand, the low number of victims identified by this study may be a reflection of the difficulty in identifying such youth. To this end, only three youth in the entire sample had prior prostitution charges. Prior research has found that victims of DMST either do not, or are unable to, self-identify (Ashley, 2008; Smith et al., 2009) and are arrested on masking charges (Ashley, 2008; Finkelhor \& Ormrod, 2004; Smith et al., 2009). The victims identified in this study represent 'sheep in wolves' clothing' wherein their delinquency is both a symptom and mask of their underlying victimization making identification extremely difficult.

With that said, an FBI Operation Cross Country sting operation in Portland, OR in November, 2010 only led to the recovery of three DMST victims over a three day period (FBI, 2010). Portland, a part of Multnomah County, has gained a national reputation as being "a hub for the sexual exploitation of children" (Rather, 2010) even though there are no reliable data to suggest this. According to the Oregon Department of Human Services, Multnomah County has identified 165 youth who have either been pimped, trafficked, or otherwise been involved in the sex trade since 2007 (Hannah-Jones, 2011). The Clark County Juvenile Department is located roughly 9 miles north from downtown Portland, just off of what has been termed the "I-5 corridor" on "the northwest circuit". The failure 
of this study to identify large numbers of victims is consistent with both the low number of victims identified by expansive, multi-agency sting operations and the low number of victims known to social service agencies.

Fourth, an examination of the risk factors identified within the Tier 1 interviews of confirmed victims reveals wide variation. While some confirmed victims had multiple risk factors, others had relatively few. For example, the only risk factor identified in the Tier 1 interview of confirmed victim number three was that she had previously run away three times. It is unclear why this youth was identified as at risk and subsequently referred to a Tier 2 when other youth were not. This suggests that other factors not captured in the screening interview may have influenced staff member perceptions of the youth and corresponding referral decisions. Perhaps staff were familiar with certain youth and aware of other factors not captured in the Tier 1 interview that explained the presence of certain risk factors. A complication in identifying DMST youth is how many youth in general, including those who suffer from drug addiction, have alternative living arrangements, or are on the run to avoid being picked up on their warrants, have risk factors that mirror those of DMST youth.

Lastly, no male victims were identified or confirmed during the study. Official data (UCR, 2009), juvenile prostitution studies (Finkelhor \& Ormrod, 2004; Mitchell et al., 2010; OJJDP, 2002; Spangenberg, 2001), commercial sexual exploitation of children studies (Ashley, 2008; Curtis et al., 2008), and studies of runaway and homeless youth (Greene et al., 1999) consistently indicate that male youth are involved in, and victims of, commercial sexual exploitation. In light of prior research, it is plausible to assume that 
male victims came through detention and were subsequently not identified. To this end, two male youth with prior prostitution charges did come through detention during the course of the study. According to probation staff, the two males were arrested by Washington State Patrol at a truck stop in the same incident where they were said to be holding a sign indicating they would have sex for money. Why these boys were not referred for additional screening cannot be determined.

One explanation may be a possible gender bias on the part of either staff and/or Shared Hope's training materials and screening instruments. Although Shared Hope acknowledges that both male and transgender youth have been identified as DMST victims, for the purpose of their practitioners guide, intake tool, and trainings they conduct, "the DMST victim population [is] referred to as female... [and] the use of the male pronoun [is used] in reference to the trafficker/pimp" (Intervene, 2010, p. 2). Training facilitated by Shared Hope, in conjunction with deep rooted notions of who constitutes a "victim" rather than an "offender" in the eyes of detention and probation staff, may have played a role in the failure to identify male victims.

In light of the limitations, the present study was the first of its kind to attempt to systematically identify DMST victims in a juvenile detention setting and facilitated the identification of six new victims. In addition to youth disclosing sexual exploitation, the screening process also resulted in a portion of youth disclosing a variety of maltreatment including physical abuse, sexual abuse, sexual assault, and domestic violence allowing staff to make proper referrals to services and resources. This is something to consider for future attempts to identify DMST victims. 
Screening youth in juvenile detention for sexual exploitation has important implications for both juvenile departments and the youth they serve. Many at risk youth are arrested each year and never go on to receive either formal probation or a sentence. For some youth, juvenile detention is a onetime occurrence. According to the 2009 Washington State Juvenile Justice Annual Report, of the 46,962 cases referred to the prosecutor in 2008, 38\% were handled through diversion and an additional $9 \%$ had no action taken. Detention officers have unique access to youth brought in by arresting agencies who: (1) do not qualify to be held (i.e. screen and release), (2) are later handled informally through diversion, or (3) have their charges dropped. Screening all youth during intake, as opposed to only those more deeply involved the juvenile justice system, provides the opportunity to screen a larger number of at risk youth who would not otherwise be screened. In addition, screening youth at this stage facilitates early identification. Only through identification can victims be diverted from the formal juvenile justice system and linked to the appropriate social, mental, and health services in the community.

Early identification is also fiscally responsible. Each youth currently costs Clark County an average of $\$ 200$ per day to detain and parents $\$ 40$ for each day their child is in custody. The six victims, prior to being identified in this study, had collectively spent 325 days in custody at a cost of $\$ 65,000$ to the county (not including court costs) and $\$ 13,000$ to the parents. How much of this is a direct result of their victimization cannot be determined as it was not the focus of the present study. However, what is clear is that the financial expenses associated with unidentified youth are high. Moreover, the 
trajectory of delinquency would have likely continued had it not been for the identification of their victimization.

When youth are delinquent as a result and manifestation of their victimization, traditional approaches are not effective as they target the youth's delinquency and not the underlying causes. While this claim can be made for juvenile delinquents in general, unidentified DMST youth are viewed, classified, and treated as delinquents when in reality, they are victims who require and deserve a plethora of services. Furthermore, releasing these youth back into the environment where they are being exploited ensures continued victimization, especially for those being sexually exploited by their own family.

DMST has certainly been established as a reality for an unknown number of youth. The current study found that $1.9 \%$ of youth who came through detention were victims of DMST. The above mentioned prevalence rate needs to be couched in the context from which it was derived. The number of victims identified in this study does not reflect the actual number of DMST involved youth in general as only those who came through detention during the course of the study were screened. Furthermore, although all youth were screened, it is likely that a proportion of DMST victims presented as false negatives and were subsequently not identified during the process. The findings of this study are also site specific and may not generalize to other locations. Despite these limitations, we are left with more information than we had before.

Prevalence estimates continue to be highly dramatic and rely on figures taken out of context. A 2010 national threat assessment report to Congress by the USDOJ states 
that from 2004 to 2008, Federal Internet Crimes Against Children (ICAC) Task Forces "noted a more than thousand percent increase in complaints of child prostitution" (p. 8). While there was no caveat attached to the statement, it came 24 pages later: "it is not known to what extent that increase is explained by increased awareness as opposed to increased frequency of the crime" (p. 32). Regarding actual victims, national efforts since 2003 have "resulted in recovering 918 children and 554 state and federal convictions of those who prostitute our children" (p. 32). It is important to note that the report addressed multiple forms of child sexual exploitation of which prostitution is just one form.

The difficulty in identifying DMST victims in addition to the low number of victims identified through rigorous attempts support the need for better measures. We need to continue to refine our process to strategically and empirically identify DMST victims. Future research should attempt to use a tiered screening process to identify victims in other settings where victims are likely to be found. As the findings of this study demonstrate, agencies such as human services and child protection services have unidentified victims on their case loads. Prior research has also shown that homeless shelters and non-profit organizations serving at risk youth have unidentified victims amongst their populations.

As a society, we cannot simply rely on victims coming to the attention and detection of law enforcement. As it stands, the current inability of agencies and organizations to identify DMST victims cannot be used to claim that they do not exist. Conversely, in the absence of better measures, there continues to be no valid, empirical evidence to support such headlines as "Child Sex Trafficking Growing in the U.S." 
(Khan, 2010) that only serve to create moral panic. DMST and child sexual exploitation have been on the national agenda for a number of years now. So far, an increase in victim identification is the result of enhanced awareness, interest, and funding, and cannot itself be used to prove that the rate of DMST is any greater today than it was 10 to 20 years ago. 
Table 1. Demographic characteristics of youth receiving Tier $I(N=535)$.

\begin{tabular}{|c|c|c|}
\hline & $f$ & $\%$ \\
\hline \multicolumn{3}{|l|}{ Gender } \\
\hline Male & 380 & 71.0 \\
\hline Female & 152 & 28.4 \\
\hline Unknown & 3 & .6 \\
\hline \multicolumn{3}{|l|}{ Race } \\
\hline White & 390 & 72.9 \\
\hline Black & 59 & 11.0 \\
\hline Hispanic & 50 & 9.3 \\
\hline Other & 13 & 2.4 \\
\hline Unknown & 23 & 4.3 \\
\hline \multicolumn{3}{|l|}{ Age } \\
\hline $9-12$ & 15 & 2.9 \\
\hline 13 & 21 & 3.9 \\
\hline 14 & 72 & 13.5 \\
\hline 15 & 103 & 19.3 \\
\hline 16 & 137 & 25.6 \\
\hline 17 & 154 & 28.6 \\
\hline 18 & 25 & 4.7 \\
\hline 19 & 5 & .9 \\
\hline Unknown & 3 & .6 \\
\hline
\end{tabular}


Table 2. Number of youth receiving one or more Tier 1 interviews.

\begin{tabular}{lcc}
\hline Number of Times Received Tier 1 & $f$ & $\%$ \\
\hline 1 & 389 & 72.7 \\
More than 1 & 146 & 27.3 \\
2 & 103 & 19.3 \\
3 & 33 & 6.2 \\
4 & 7 & 1.3 \\
5 & 2 & .4 \\
6 & 1 & .2 \\
\hline Total Number of Youth & 535 & 100.0 \\
\hline
\end{tabular}


Table 3. Characteristics of youth referred to a Tier 2 interview $(N=47)$.

$f \quad \%$

Gender

Male

13

27.7

Female

34

72.3

Race

White

39

83.0

Black

3

6.4

Hispanic

3

6.4

Unknown

2

4.3

Age

13

4

8.5

14

5

10.6

15

11

23.4

16

15

31.9

17

11

23.4

18

1

2.1

Reason for youth's arrest/detention

New Charge(s)

13

27.7

P.V. \&/Or Warrant

28

59.6

Serving a Sentence

4

8.5

Other

2

4.2 
Table 4. Chi-square and Pearson's $r$ values for Tier 1 variables and whether or not youth was referred to a Tier 2.

\begin{tabular}{|c|c|c|c|c|}
\hline & $\begin{array}{c}\% \text { of Tier } 1 \text { 's } \\
\text { Referred to } \\
\text { Tier } 2 \\
(n=47)\end{array}$ & $\begin{array}{c}\% \text { of Tier } 1 \text { 's } \\
\text { Not Referred } \\
\text { to Tier } 2 \\
(n=664)\end{array}$ & $\chi^{2}$ & $r$ \\
\hline Gender $(n=708)$ & & & $56.78 * * *$ & $.283^{* *}$ \\
\hline Male & 27.7 & 77.5 & & \\
\hline Female & 72.3 & 22.5 & & \\
\hline Living Situation Risk $(n=474)$ & & & $24.36^{* * *}$ & $.227^{* *}$ \\
\hline No & 66.7 & 92.5 & & \\
\hline Yes & 33.3 & 7.5 & & \\
\hline $\begin{array}{l}\text { Ever Run Away from Home } \\
(n=710)\end{array}$ & & & $51.45 * * *$ & $.269 * *$ \\
\hline No & 10.6 & 63.7 & & \\
\hline Yes & 89.4 & 36.3 & & \\
\hline $\begin{array}{l}\text { Ever Been in Foster Care } \\
(n=707)\end{array}$ & & & $34.08 * * *$ & $.220 * *$ \\
\hline No & 57.4 & 88.0 & & \\
\hline Yes & 42.6 & 12.0 & & \\
\hline $\begin{array}{l}\text { CPS/DSHS Currently Involved } \\
(n=679)\end{array}$ & & & $52.29 * * *$ & $.278 * *$ \\
\hline No & 52.3 & 89.8 & & \\
\hline Yes & 47.7 & 10.2 & & \\
\hline Police Contacts & & & & \\
\hline $\begin{array}{l}\text { Outside of Clark County } \\
(n=590)\end{array}$ & & & $17.29 * * *$ & $.171^{* *}$ \\
\hline No & 62.8 & 86.5 & & \\
\hline Yes & 37.2 & 13.5 & & \\
\hline In a State Other than & & & $11.24 * *$ & $.138^{* *}$ \\
\hline Washington $(n=586)$ & & & & \\
\hline No & 72.1 & 89.3 & & \\
\hline Yes & 27.9 & 10.7 & & \\
\hline In Oregon $(n=586)$ & & & $11.89^{* *}$ & $.142 * *$ \\
\hline No & 74.4 & 91.0 & & \\
\hline Yes & 25.6 & 9.0 & & \\
\hline $\begin{array}{l}\text { Visual Evidence of Brands/Tattoos } \\
(n=688)\end{array}$ & & & $6.50^{* *}$ & $.097 *$ \\
\hline No & 75.0 & 88.2 & & \\
\hline Yes & 25.0 & 11.8 & & \\
\hline Evidence of Abuse $(n=685)$ & & & $4.33^{*}$ & $.080^{*}$ \\
\hline No & 93.0 & 98.0 & & \\
\hline Yes & 7.0 & 2.0 & & \\
\hline $\begin{array}{l}\text { DMST Status as Perceived by Tier } 1 \\
\text { Interviewer }(n=445)\end{array}$ & & & $82.76 * * *$ & $.431^{* *}$ \\
\hline Non-Disclosed; Not Suspected & 65.4 & 98.6 & & \\
\hline Non-Disclosed; Suspected Victim & 34.6 & 1.4 & & \\
\hline
\end{tabular}

${ }^{*} p<.05 . * * p<.01 . * * * p<.001$.

Note: Coding Scheme $(0=$ Male, $1=$ Female $) ;(0=$ No, $1=$ Yes $) ;(0=$ Non-Disclosed; Not Suspected, 1 = Non-Disclosed; Suspected Victim) 


\begin{tabular}{|c|c|c|c|c|c|c|c|c|c|c|c|c|c|}
\hline 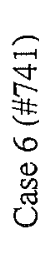 & & $\stackrel{n}{\sim}$ & $\begin{array}{l}\text { 旁 } \\
\text { 点 }\end{array}$ & $\begin{array}{l}\text { 葋 } \\
\text { 荧 }\end{array}$ & & $\stackrel{\circ}{z}$ & 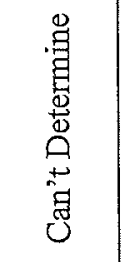 & 6 & $\stackrel{\circ}{Z}_{1}$ & 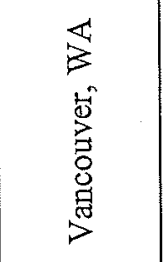 & 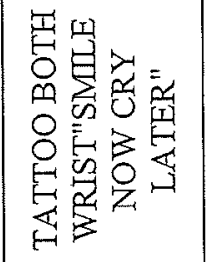 & & $\begin{array}{l}0 \\
\text { Z }\end{array}$ \\
\hline 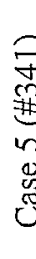 & & $\stackrel{\Xi}{\Xi}$ & 总 & 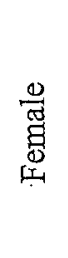 & & $\stackrel{\circ}{z}$ & 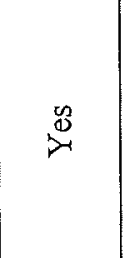 & 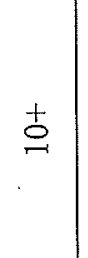 & $\stackrel{\infty}{\infty}$ & 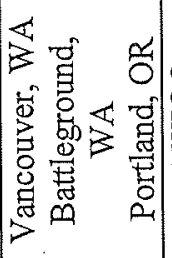 & 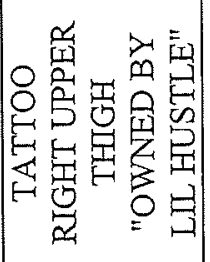 & & 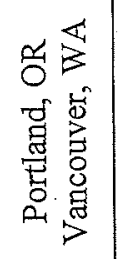 \\
\hline $\begin{array}{l}6 \\
6 \\
0 \\
7 \\
7 \\
0 \\
0 \\
0\end{array}$ & & 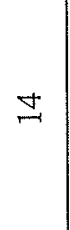 & $\begin{array}{l}\text { 兽 } \\
\text { 歺 }\end{array}$ & 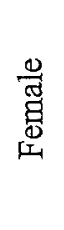 & & $\stackrel{d}{\Delta}$ & 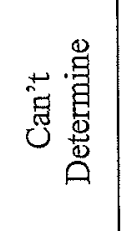 & $\nabla$ & ${ }_{2}^{\mathscr{3}}$ & 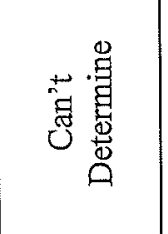 & 总 & & 苇 \\
\hline 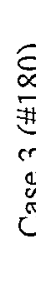 & & $\stackrel{n}{n}$ & 营 & 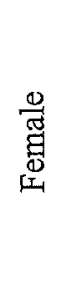 & & 吕 & $\ddot{z}_{1}$ & en & 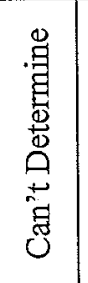 & 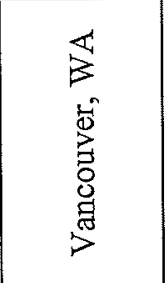 & 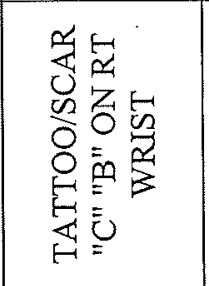 & & 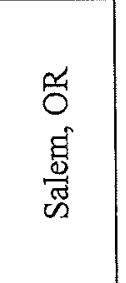 \\
\hline 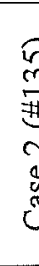 & & 등 & $\begin{array}{l}\text { E } \\
\text { 夏 } \\
\text { 点 }\end{array}$ & 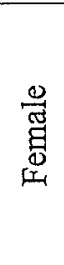 & & $\underbrace{0}_{2=1}$ & 若 & $\stackrel{ }{-}$ & 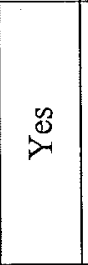 & 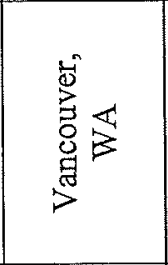 & 苋 & & 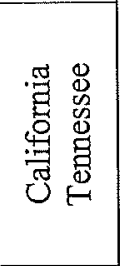 \\
\hline $\begin{array}{l}8 \\
5 \\
\\
8 \\
8\end{array}$ & & \pm & $\begin{array}{l}\text { 曽 } \\
\text { 点 }\end{array}$ & 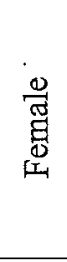 & & 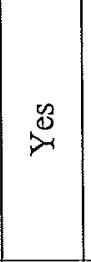 & $\stackrel{\infty}{\infty}$ & $t$ & $\sum_{2-1}^{\infty}$ & 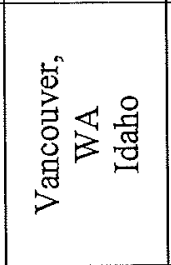 & 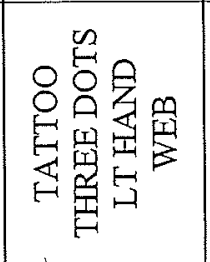 & & 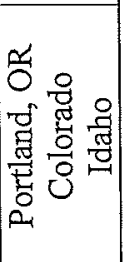 \\
\hline & 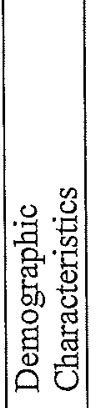 & $\stackrel{8}{80}$ & 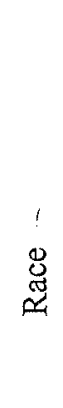 & $\begin{array}{l}\overline{0} \\
\overline{0} \\
0\end{array}$ & 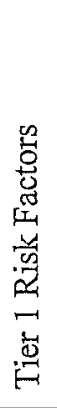 & 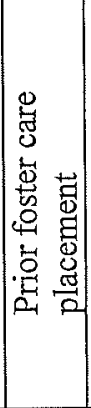 & 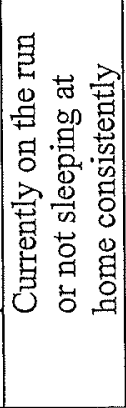 & 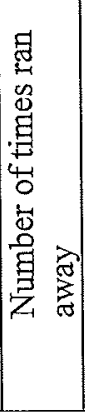 & 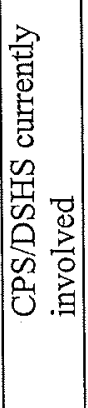 & 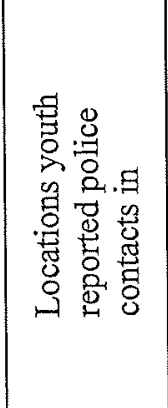 & 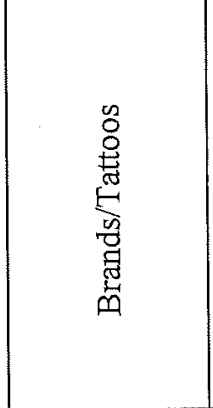 & 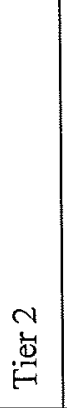 & 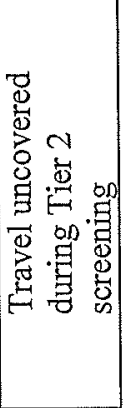 \\
\hline
\end{tabular}




\begin{tabular}{|c|c|c|c|c|c|c|c|c|c|c|}
\hline 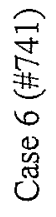 & 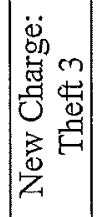 & m & in & in & $\begin{array}{l}0 \\
\text { Z } \\
Z\end{array}$ & $n$ & m & $\begin{array}{l}8 \\
\infty \\
\infty \\
\text { s }\end{array}$ & $\begin{array}{l}\stackrel{8}{0} \\
\stackrel{n}{n} \\
\dot{s}\end{array}$ & 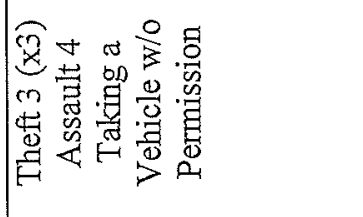 \\
\hline 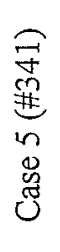 & 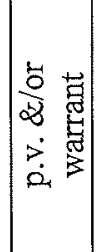 & $\checkmark$ & 0 & $n$ & $\begin{array}{l}\text { 总 } \\
\text { 乙 }\end{array}$ & $\infty$ & $\underset{t}{ \pm}$ & 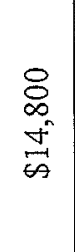 & $\begin{array}{l}8 \\
8 \\
0 \\
6\end{array}$ & 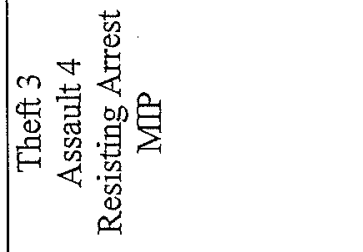 \\
\hline 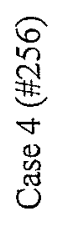 & 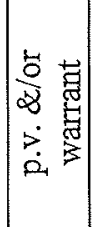 & $\sigma$ & $\nabla$ & in & $\begin{array}{l}\text { 号 } \\
\text { 年 }\end{array}$ & $\infty$ & $n$ & $\begin{array}{l}8 \\
8 \\
0 \\
0 \\
0\end{array}$ & 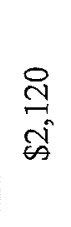 & 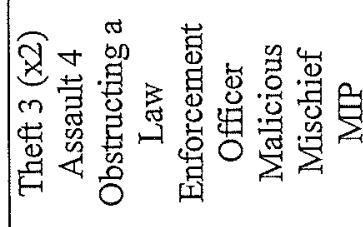 \\
\hline $\begin{array}{l}\text { } \\
\infty \\
\mathbb{\#} \\
m \\
0 \\
0 \\
\tilde{J} \\
\tilde{J}\end{array}$ & 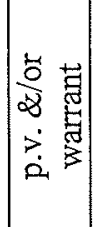 & - & $N$ & $\nabla$ & 惫 & $r$ & $\vec{n}$ & 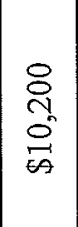 & $\begin{array}{l}\text { O্ } \\
\text { : } \\
\text { Ĉ }\end{array}$ & 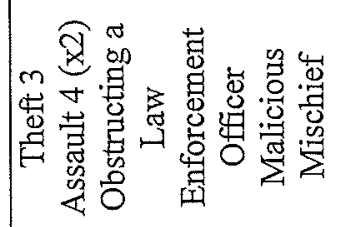 \\
\hline 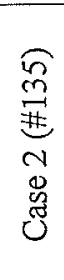 & 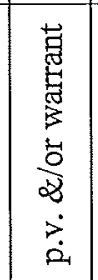 & $\sim$ & $N$ & $r$ & 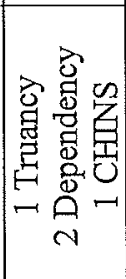 & $\infty$ & तु & 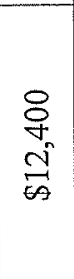 & \begin{tabular}{l}
$\stackrel{8}{\infty}$ \\
$\stackrel{+}{+}$ \\
\multirow{\infty}{*}{}
\end{tabular} & 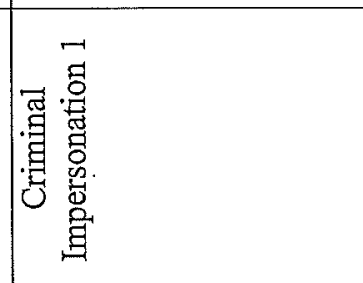 \\
\hline 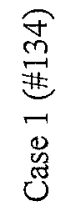 & 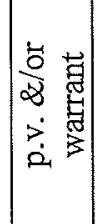 & m & $n$ & in & 总 & $\infty$ & $\mathscr{q}$ & $\begin{array}{l}\stackrel{8}{0} \\
\stackrel{2}{\circ}\end{array}$ & 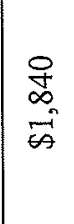 & 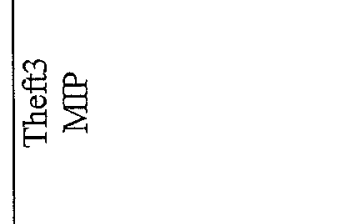 \\
\hline & 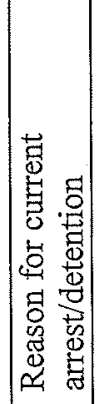 & 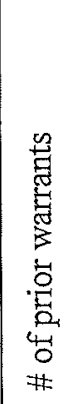 & 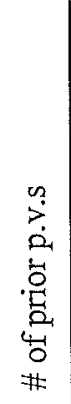 & 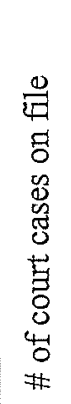 & 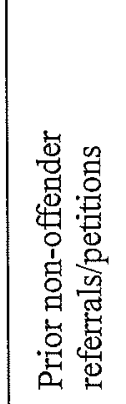 & 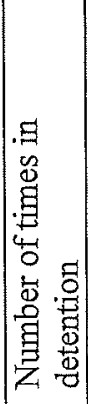 & 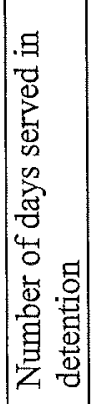 & 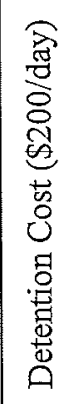 & 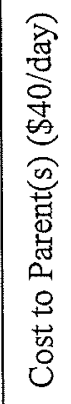 & 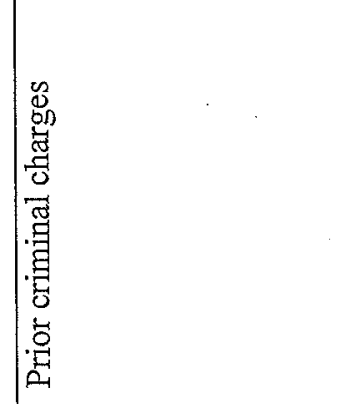 \\
\hline
\end{tabular}




\section{References}

Ashley, J. (2008). The commercial sexual exploitation of children and youth in Illinois. Chicago, IL: Illinois Criminal Justice Information Authority. Retrieved from http://www.icjia.state.il.us/public/pdf/ResearchReports/CSEC\%202008\%20ICJIA $\% 20$ REPORT.pdf

Boxill, N. A., \& Richardson, D. J. (2007). Ending sex trafficking of children in Atlanta. Affilia, 22, 138-149.

Clawson, H. J., Dutch, N. M., Salomon, A., \& Grace, L. G. (2009). Study of HHS programs serving human trafficking victims: Final report. Washington DC: U.S. Department of Health \& Human Services. Retrieved from http://aspe.hhs.gov/hsp/07/HumanTrafficking/Final/index.pdf

Colby, I. (2011). Runaway and throwaway youth: Time for policy changes and public responsibility. Journal of Applied Research on Children: Informing Policy for Children at Risk, 2(1), 1-11.

Comaroff, J, \& Comaroff, J. L. (2006). Figuring crime: Quantifacts and the production of the un/real. Public Culture, 18, 209-246.

Curtis, R., Terry, K., Dank, M., Dombrowski, K., \& Khan, B. (2008). The commercial sexual exploitation of children in New York City, Volume 1: The CSEC population in New York City: Size, characteristics, and needs. New York, NY: Center for Court Innovation. Retrieved from http://www.ncjrs.gov/pdffiles1/nij/grants/225083.pdf

David, F. (2010). Building the infrastructure of anti-trafficking: Information, funding, responses. Criminology \& Public Policy, 9, 235-243.

Farrell, A., McDevitt, J., \& Fahy, S. (2010). Where are all the victims? Understanding the determinants of official identification of human trafficking incidents. Criminology \& Public Policy, 9, 201-231.

Federal Bureau of Investigation (FBI; n.d.). Federal statutes relating to crimes against children: Title 18 of the United States Code. Retrieved from http://www.fbi.gov/hq/cid/càc/federal.htm

Federal Bureau of Investigation (FBI), Uniform Crime Report (UCR; 2010). Crime in the United States 2009. Washington, DC: FBI Retrieved from http://www2.fbi.gov/ucr/cius2009/about/index.html 
Federal Bureau of Investigation (FBI), Portland. (2010, November 8). FBI, local agencies target child sex trafficking in weekend sting: Operation cross country V (Press Release). Retrieved from http://portland.fbi.gov/pressrel/pressrel10/pd110810.htm

Finkelhor, D., \& Ormrod, R. (2004). Prostitution of juveniles: Patterns from NIBRS. OJJDP Juvenile Justice Bulletin, pp. 1-11. Washington, DC: USDOJ. Retrieved from http://www.ncjrs.gov/pdffiles1/ojjdp/203946.pdf

Goode, E., \& Ben-Yehuda, N. (1994). Moral panics: Culture, politics, and social construction. Annual Review of Sociology, 20, 149-171.

Gelles, R. J. (1980). Violence in the family: A review of research in the seventies. Journal of Marriage and Family, 42, 873-885.

Glosser, A., Gardiner, K., \& Fishman, M. (2004). Statutory rape: A guide to state laws and reporting requirements. Falls Church, VA: The Lewin Group. Retrieved from http://www.lewin.com/content/publications/3068.pdf

Gozdziak, E. M., \& Bump, M. N. (2008). Data and research on human trafficking: Bibliography of research-based literature: Final report. Washington, DC: Institute for the Study of International Migration. Retrieved from http://www.ncjrs.gov/pdffiles1/nij/grants/224392.pdf

Greene, J. M., Ennett, S. T., \& Ringwalt, C. L. (1999). Prevalence and correlates of survival sex among runaway and homeless youth. American Journal of Public Health, 89, 1406-1409.

Hammer, H., Finkelhor, D., \& Sedlak, A. J. (2002). Runaway/thrownaway children: National estimates and characteristics. National Incidence Studies of Missing, Abducted, Runaway, and Thrownaway Children (NISMART)., pp. 1-12. Washington, DC: USDOJ. Retrieved from http://www.ncjrs.gov/pdffiles1/ojjdp/196469.pdf

Hammer, H., Finkelhor, D, Sedlak, A. J., \& Porcellini, L. E. (2004). National estimates of missing children: Selected trends, 1988-1999. National Incidence Studies of Missing, Abducted, Runaway, and Thrownaway Children (NISMART), pp. 1-8. Washington, DC: USDOJ. Retrieved from http://www.ncjrs.gov/pdffiles1/ojjdp/206179.pdf

Hannah-Jones, N. (2011, January 13). Analysis: Despite reputation, no proof Portland is a hub for child sex trafficking. The Oregonian. Retrieved from http://www.oregonlive.com/portland/index.ssf/2011/01/portland_child_sex_traffic king.html 
Khan, H. (2010, May 5). Child sex trafficking growing in the U.S.: 'I got my childhood taken from me'. ABC News. Retrieved from http://abcnews.go.com/US/domesticsex-trafficking-increasing-united-states/story?id=10557194

Leitch, L., \& Snow, M. A. (2010). Domestic minor sex trafficking: Practitioner guide and intake tool. Arlington, VA: Shared Hope International.

Mitchell, K. J., Finkelhor, D., \& Wolak, J. (2010). Conceptualizing juvenile prostitution as child maltreatment: Findings from the national juvenile prostitution study. Child Maltreatment, 15, 18-36.

Rather, D. (2010, May 18). Pornland, Oregon: Child prostitution in Portland. The Huffington Post. Retrieved from http:/www.huffingtonpost.com/danrather/pornland-oregon-child-pro_b_580035.html?view=print

Robertson, S. (2008a). Age of consent laws. In Children and Youth in History (Item \#230). Retrieved from http://chnm.gmu.edu/cyh/teaching-modules/230

Robertson, S. (2008b). Age of consent laws. In Children and Youth in History (Item \#230). Retrieved from http://chnm.gmu.edu/cyh/teachingmodules $/ 230$ ? section $=$ primarysources $\&$ source $=24$

Scott, M. S., \& Dedel, K. (2006). Problem-Oriented Guides for Police; Problem-Specific Guides Series No. 2; Street Prostitution (2nd Ed.). Office of Community Oriented Policing Services (COPS), pp. 1-90. Washington, DC: USDOJ. Retrieved from http://www.cops.usdoj.gov/pdf/pop/e10062633.pdf

Sedlak, A. J., Finkelhor, D., Hammer, H., \& Schultz, D. J. (2002). National estimates of missing children: An overview. National Incidence Studies of Missing, Abducted, Runaway, and Thrownaway Children (NISMART), pp. 1-12. Washington, DC: USDOJ. Retrieved from http://www.missingkids.com/en_US/documents/nismart2_overview.pdf

Smith, L. A., Vardaman, S. H., \& Snow, M. A. (2009). The national report on domestic minor sex trafficking: America's prostituted youth. Arlington, VA: Shared Hope International.

Spangenberg, M. (2001). Prostituted youth in New York City: An overview. End Child Prostitution, Child Pornography, and Trafficking of Children for Sexual Purposes. Brooklyn, NY: ECPAT-USA. Retrieved from http://www.hawaii.edu/hivandaids/Commercial\%20Sexual\%20Exploitation\%20of $\% 20$ Young\%20People\%20in\%20New\%20York\%20City.pdf 
Stolz, B. A. (2010). Human trafficking: Policy. Criminology \& Public Policy, 9, 267-274.

Tyldum, G., \& Brunovskis, A. (2005). Describing the unobserved: Methodological challenges in empirical studies on human trafficking. International Migration, 43, 17-34.

Tyler, K. A., Hoyt, D. R., \& Whitbeck, L. B. (2000). The effects of early sexual abuse on later sexual victimization among female homeless and runaway adolescents. Journal of Interpersonal Violence, 15, 235-250.

U.S. Department of Justice (2010). The national strategy for child exploitation prevention and interdiction: A report to Congress. Washington, DC: USDOJ. Retrieved from http://www.projectsafechildhood.gov/docs/natstrategyreport.pdf

U.S. Department of Justice, Office of Justice Programs, Office of Juvenile Justice and Delinquency Prevention (OJJDP; 2002). Female juvenile prostitution: Problem and response. Alexandria, VA: National Center For Missing and Exploited Children. Retrieved from http://www.missingkids.com/en_US/publications/NC68.pdf

Victims of Trafficking and Violence Protection Act (TVPA), 22 U.S.C. $§ 7102$ (2000). Retrieved from http://www.state.gov/documents/organization/10492.pdf

Victims of Trafficking and Violence Protection Act (TVPA), 22 U.S.C. $§ 7109$ (2000). Retrieved from http://www.state.gov/documents/organization/10492.pdf

Washington State Department of Social and Health Services (DSHS), Partnership Council of Juvenile Justice (WA-PCJJ). (2011). 2009 juvenile justice annual report. Olympia, WA: Office of Juvenile Justice. Retrieved from http://www.dshs.wa.gov/ojj/annual_report.shtml

Weiner, N. A., \& Hala, N. (2008). Measuring human trafficking: Lessons from New York City. New York, NY: Vera Institute of Justice. Retrieved from http://www.ncjrs.gov/pdffiles1/nij/grants/224391.pdf

William Wilberforce Trafficking Victims Protection Act Reauthorization of 2008, H. R. 7311 (2008). Retrieved from http://www.justice.gov/olp/pdf/wilberforce-act.pdf

Willis, B. M., \& Levy, B. S. (2002). Child prostitution: Global health burden, research needs, and interventions. The Lancet, 359, 1417-1422. 
Appendix A: Tier 1 Interview

\section{YOUTH SEX TRAFFICKING \\ DETENTION SCREENING INTERVIEW \\ TIER ONE \\ Version 2: May 19, 2010}

\begin{tabular}{|l|l|l|}
\hline \multicolumn{2}{|l|}{ YOUTH NAME: } & JUVIS NUMBER: \\
\hline DOB: & RGE: & INTERVIEW DATE: \\
\hline INTERVIEWER NAME: & INTERVIEWER SEX: $\square$ Male $\square$ Female \\
\hline $\begin{array}{l}\text { REFERRALS MADE: (Check all that apply) } \\
\square \text { Law Enforcement } \square \text { CPS/DSHS } \square \text { Probation } \square \text { Advocate } \\
\square \text { Other }\end{array}$ & COMMENTS REGARDING REFERRALS: \\
\hline
\end{tabular}

Directions: Staff completing thís tool should (1) ask each question in the interview and indicate "NR" if the youth refuses to respond after prompting, and (2) be aware of the attitude and demeanor of the youth during the interview and record observations at the end of the tool.

1. Where are you living right now? Is this where you are sleeping too?

2. Are you living with anyone? $\square$ No $\square$ Yes (Ask Question 2a)

2a. Who are you living with?

3. Where are you from originally?

4. Have you ever run away from home? $\square$ No $\quad \square$ Yes (Ask Question 4a)

4a. About how many times have you run away? (If youth has difficulty, ask if one time,

2-3 times, 4-6 times, 6-10 times, more than 10)

5. Have you ever been in foster care? $\square$ No $\square$ Yes

6. Does someone take care of you when you need help? $\square$ No $\quad \square$ Yes (Ask Question 6a)

6a. Who takes care of you? 
7. Have you had any contacts with police before you came here? $\quad$ No $\quad \square$ Yes (Ask Questions 7a-7c)

7a. About how many contacts with police have you had? (If youth has difficulty, ask if one time, 2-3 times, 4-6 times, 6-10 times, more than 10)

7b. What cities did these police contacts take place?

7c. How many of these contacts resulted in your arrest? (If youth has difficulty, ask if one time, 2-3 times, 4-6 times, 6-10 times, more than 10)

\section{READ TO YOUTH AT THE END OF THE INTERVIEW?}

Another custody staff member is going to review the answers you give me after I put this sheet in a lockbox that only they have access to. If they need more clarification on some of your answers, they might ask to talk with you a little more. At that point, you can decide whether you want to talk with them. OK?

INTERVIEWER OBSERVATIONS:

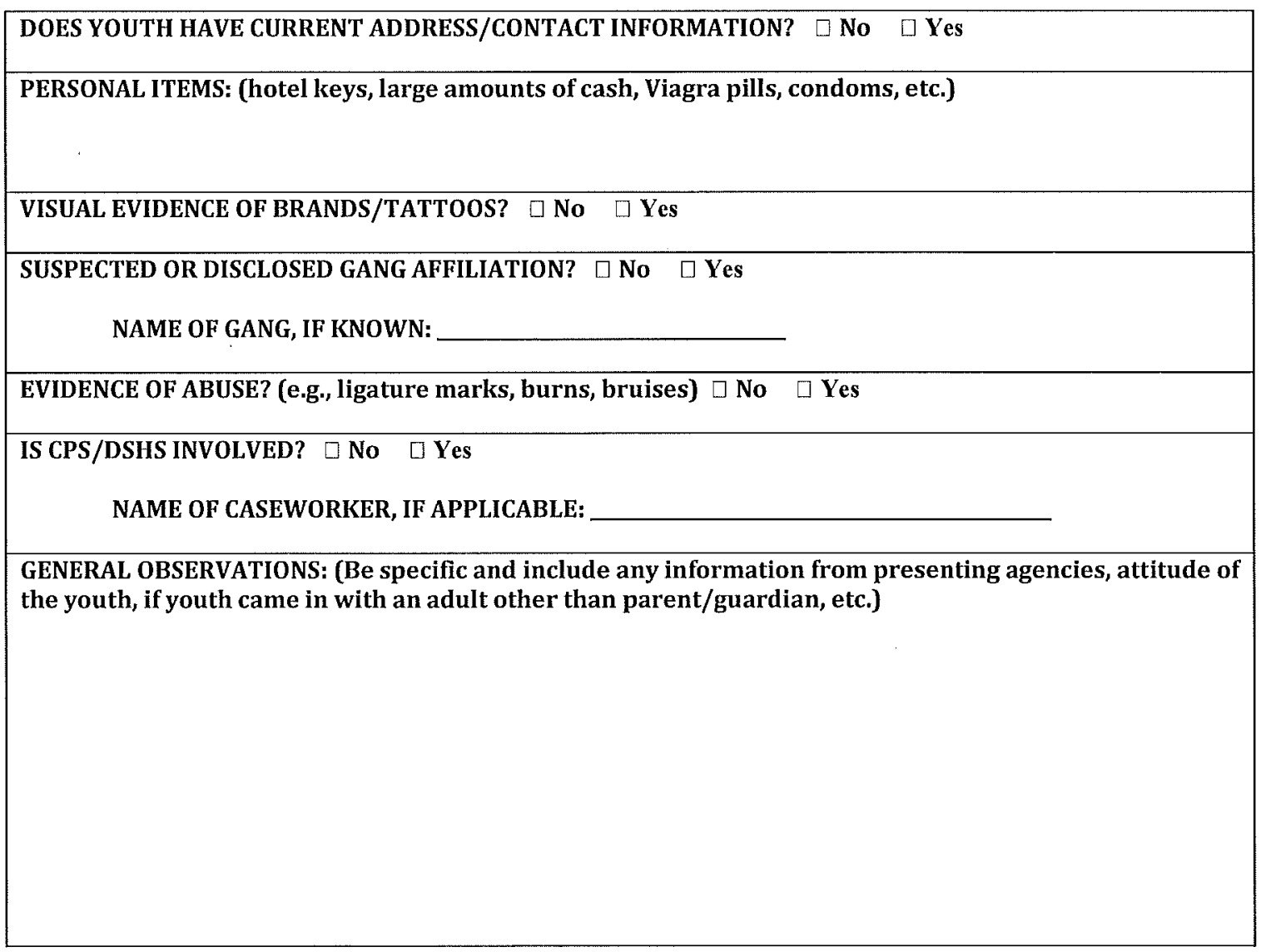


Appendix B: Tier 2 Interview

\section{RESPONSE TEAM INTERVIEW \\ TIER TWO \\ Version 1: June 4, 2010}

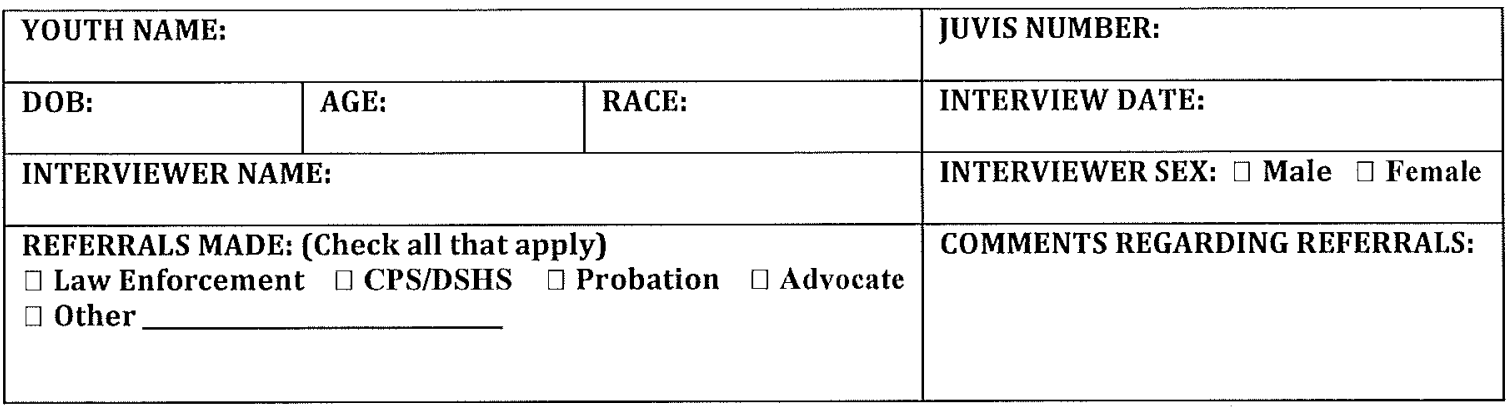

\section{LIVING SITUATION}

1. Where are you from? Is this where you live now?

2. Do you currently live with your parents? If not, where do you live and with whom?

3. What is your relationship like with your parents/guardians and siblings?

4. Have you ever been in foster care?

5. Are you currently in foster care?

5a. How long have you been in foster care?

6. When things got tough while in foster care, what strengths and resources helped you deal with it?

\section{SCHOOL}

7. Do you go to school? What subjects do you like/dislike?

8. Are you involved in any activities at school? (If yes, What activities? If no, Do you wish you were involved in any activities?) 


\section{RUNAWAY HISTORY}

9. Have you ever left home without your parents or guardians knowing?

9a. Why did you leave home?

10. How many times have you run away?

(SKIP TO NEXT SECTION "ARREST HISTORY” IF NO RUNWAY HISTORY)

10a. Where do you like to go when you run away?

$10 \mathrm{~b}$. What were some of the ways you took care of yourself while you were away from home?

10c. Did you ever do any traveling while you were gone?

10ci. What places did you go? Can you describe what you saw?

10cii. While traveling, who did you go with? How did you get from one place to the next?

10ciii. How long were you gone?

$10 \mathrm{~d}$. While you were away from home did anything keep you from going back?

10e. While you were away from home did you experience anything that made you uncomfortable or scared?

10f. Do you feel safe now?

10g. Do you have a best friend? Who is that?

\section{ARREST HISTORY}

11. What have you been arrested for? (e.g., curfew violations, skipping school, drugs, running away, skipping school) Explain. 
12. What happened when you were arrested?

13. Was there a person you could count on to help you through the experience? How did you know you could rely on them?

\section{PARTNER SITUATION}

14. Do you have a boyfriend or girlfriend? (SKIP TO NEXT SECTION “TATTOOS” IF NO PARTNER)

14a. How did you meet?

$14 \mathrm{~b}$. What do you two do for fun? Where do you go?

14c. Every couple has problems-what are some things about your relationship that you don't like?

$14 \mathrm{~d}$. What are some of the things he/she does to show you they care for you?

14e. How old is he/she?

\section{TATTOOS (only if visible)}

15. What does your tattoo mean?

16. When did you get it?

17. Was someone there while you got it? Who?

'Be Completed By Response Team Only: O Self-Disclosed Victim Don-Disclosed; Suspected Victim
Nofer to Tier Three?
Team Member


Appendix C: Tier 3 Interview

TIER THREE INTERVIEW

Version 4: October 29, 2010

\begin{tabular}{|l|l|}
\hline JUVIS NUMBER: & DATE: \\
\hline YOUTH SEX: $\square$ Male $\square$ Female & INTERVIEWER SEX: $\square$ Male $\square$ Female \\
\hline
\end{tabular}

LIVING SITUATION: When talking with a minor about their living situation, determine where they are living and with whom, or whether they have been involved in Child Protective Services. Also, see where their parents are and the role they play in the child's life.

The following are some questions one may use during conversation to follow up on the youth's living situation:

1. Do you have contact with your parents or relatives?

2. Who do you feel closest to in your life? What is your happiest memory of them?

3. What have your foster homes been like?

4. Problems arise in many homes - was there anything negative in your living situation?

4a. Anything positive?

5. Who was your favorite foster family? What made them special?

6. Where have you lived where you felt the safest?

7. Do you feel safe where you're living now?

RUNAWAY HISTORY: If the minor has a pattern of running away or is homeless, inquire about what they do to provide for themselves on the streets. Try to have them reveal the true dynamics of this situation and the players involved.

8. How did you/do you take care of yourself while away from home?

9. Where did you stay/sleep while you were on the run? 
10. What would need to change at home to make you feel safe living there?

11. Is there anyone who looks out for you while you're on the streets?

12a. How do they do this?

12. Has anyone given you any tips on how to survive? What are some of those tips?

13. Being on the streets can get lonely. What did you do to make yourself feel better?

14. While you were away from home did anything keep you from going back?

15. Has anyone asked you to do something sexually that made you uncomfortable?

16. Does this person give you money, drugs, clothes?

17. Did you have a way to make money while on the run?

18. Are you in control of your money or has someone offered to manage that for you?

19. It takes a tough person to survive on the streets. What advice would you give to another person your age who is thinking about running away?

20. When things get tough, what part of your personality do you draw on to survive. Can you give me an example of when you did this?

21. Tell me about the time you felt proudest of yourself.

TRAVELING: Determine if the minor has traveled and where. Sometimes the minor will not know where they have traveled but can identify landmarks or recall events. Also, it is important to ascertain with whom the minor has traveled and if they were dependent on the other for expenses. Also ask about how she paid for her trip and transportation. 
22. I see you went with [name] on your trip, who is $s /$ he? Did s/he invite you to come along for the trip?

23. How did you meet this person?

24. If you traveled alone, how did you pay for the trip? Did someone pay for you or help you travel?

25. What did you expect to see and do while you were there?

26. What expectations were fulfilled? What were not?

27. I see you were gone [number] days. Did you stay in that area the whole time?

28. Did you expect to be gone for that amount of time?

29. Did you meet up with anyone else (besides the person you left with) while you were traveling? Who?

30. Was there anything that happened to you while you were away that you didn't like or expect?

31. What was your favorite experience while traveling?

32. What would your perfect vacation be?

33. How did you celebrate your last birthday?

PARTNER HISTORY: Youth rarely engage in commercial sex without being controlled or managed by an adult. Even though the youth may refer to his/her partner in a loving way it is important to unpack the dynamics of the relationship to determine whether he/she is a trafficker/pimp. It is particularly important to gauge where the youth is at in understanding the relationship and mirror language used. For example, some youth may be very aware that their partner is also their trafficker/pimp while others may feel the exploitation is temporary and will end.

34. Have you grown apart from your family or friends since starting this relationship? 
35. Does your boyfriend act jealous of your family or friends?

36. Do you live with your boyfriend currently? Does anyone else live there with you?

37. Has your boyfriend ever hurt you?

37a. What happened? Did you go to the hospital?

39. Has your boyfriend asked you to do things sexually that make you feel uncomfortable?

40. Has your boyfriend ever asked you to do things sexually with other guys?

40a. What happened?

STRENGTH-BASED QUESTIONS: These questions can be used at any point during the intake process. Some specific strength-based questions are also offered throughout each section.

41. When did you know you had survived that situation?

42. When did you know help had arrived?

43. So, you survived that situation, what can you do to avoid that in the future?

44. So, you survived that situation, what can you do to protect yourself in the future?

45. During that difficult time what strengths helped you get through it?

46. What are some of the things that helped you survive while (on the streets, getting raped, being beaten, etc.)

o Be Completed By Tier 3 Interviewer:

Self-Disclosed Víctim — Non-Disclosed; Suspected Victim 1 Non-Disclosed; Not Suspected iterviewer Name

iterviewer Comments/Observations: 


\section{Appendix D: Assent Form \\ Improving the Identification of Children's Needs in Juve nile Detention Study}

Clark Co unty Juvenile Detention a nd Portland State University are doing a study to better understand children's needs as they come through cus tody and detention. You were identified as qualifying for participation in the study through your Intake interview, and you may be eligible for additional services if you decide to participate.

\section{What Will I Have To Do?}

If you decide you want to participate, we will ask you to talk with us now for approximately 15 minutes. We may also wish to talk with you again later today or tom orrow for about 30 minutes.

\section{Are There Any Risks?}

The in terview will ask you some sensitive questions about your relationships that may make you feel unco mfortable, sad, or nervo us. If you decide you want to participate, and start feeling uncom fortable with any question, we can stop, skip the question, or end our talk. You don't have to ans wer any questions you don't want to. If you choose to answer these questions, you should know that we are required by law to report to Child Protective Services if you tell us you have been a victim of abuse or intend to harm another. But there will be no cons equences or charges brought against you for the information you give us. If you are upset after the interview and need to talk with someone, you can request to speak with a Mental Health Counselor here in detention.

\section{What Will I Get in Return?}

You may get additional services and support from community resources outside Detention by participating. Also, you would know that you are helping others who come through Detention after you because we want to improve the way we identify children's needs in detention.

\section{What Are You Doing to Protect Me?}

Your privacy and safety are very important to us. Any inform ation you give us will be kept confidential from everyone outside of detention and research staff. No one will know wh ether or not you participated. Your name and the information we write down will only be seen by us or by research staff, and will be kept in a locked filing cabinet and a locked computer which only we can open.

\section{Any Questions?}

If you have questions about this study, this form, or the in terview, you can talk to your interviewer or to the pers on leading the study in Portland (Emily Salis bury, 503-725-5238). You can also contact the Chair of the Hum an Subjects Comm ittee of Portland State Univ er sity ab out your rights as a research participant (someone who takes part in a study). Hours are 9:00 a.m. to 5:00 p.m. The office is located at Portland State University, Unitus BIdg., 6th floor, 2121 SW 4th Avenue, Portland, OR 97201. The telephone number is (503) 725-4.288/ 1-877-480-4400, or send e-mail to: hsrrc@lists.pdxedu.

\section{If I Sign, What Does It Mean?}

This is an assent form. Your signature below means that:

$>$ You have read and und erstand the form.

$>$ You are willing to take part in the study by talking with us in one, or possibly two, in terviews.

$>$ You know you do no thave to take part in this study. And even if you agree, you can change your mind at any time with no consequences.

$>$ You know that taking part in the study will notaffect how you are treated by Detention staff. They will tr eat you just the same.

Participant Signature Date

Interviewer Signature
Date
Participant Name, printed

Interviewer Name, printed 